\title{
ARTICLE
}

\section{Ring opening reactions of heterocycles with selenium and tellurium nucleophiles}

Received 00th January 20xx Accepted 00th January 20xx

DOI: $10.1039 / x 0 x x 00000 x$

\author{
Damiano Tanini and Antonella Capperucci*
}

\begin{abstract}
An overview of the preparation and synthetic potentialities of functionalized organoselenium and organotellurium compounds is presented. Various methods to generate selenated, or tellurated, nucleophiles are described. Focusing on the more recent developments, in this Perspective reactions of selenium and tellurium nucleophiles with heterocycles (O-, $\mathrm{N}$-, S-containing) of different ring size (three, four, five, six-membered) to access a variety of organo-chalcogen compounds, bearing different functional groups, are covered. Their application in organic synthesis and asymmetric catalysis is also reported, along with some novel methodologies derived thereof.
\end{abstract}

\section{Introduction}

Organoselenium and organotellurium compounds are of significant utility in organic synthesis, material sciences, food chemistry, medicinal chemistry, and biology. ${ }^{1}$

Since the pioneering studies reported by Sharpless in $1973^{2}$ on the ring opening reaction of epoxides with selenium nucleophiles, the use of chalcogens in nucleophilic ring opening reactions (NRORs) has been attracting growing interest among chemists. ${ }^{3}$ Built upon these basis, a number of procedures for the conversion of strained heterocycles into functionalised valuable chalcogen-containing molecules, including $\beta$-hydroxy-, and $\beta$-amino-selenides and tellurides, have been developed. In addition, several chalcogenmediated functional-group transformations have been reported and applied in organic synthesis and in organocatalysis. NRORs of epoxides and aziridines represent the method of choice for the synthesis of $\beta$-hydroxy and $\beta$-amino chalcogenides. These valuable compounds are versatile reagents which, owing to the possibility to selectively functionalise the carbon-chalcogen bond, find broad application in organic synthesis. For example, total syntheses of lycorine, $^{4} \quad$ (-)-galanthamine, ${ }^{5} \quad(+)$-7-deoxypancratistatin, ${ }^{6}$ and plumisclerin $A^{7}$ (Figure 1 ) all share a selenium-mediated ring opening reaction key step.
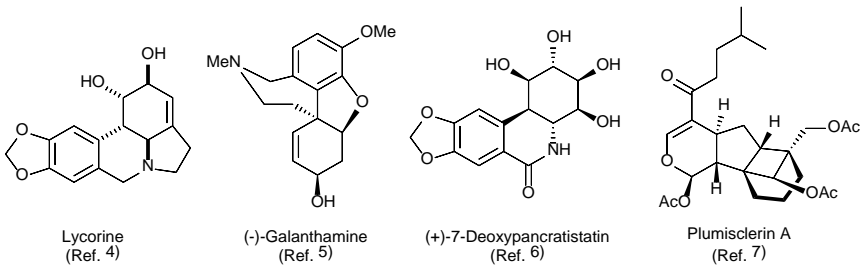

Figure 1: Natural products synthesised using Se intermediates.
Furthermore, owing to their biological properties, functionalised organoselenides and organotellurides are interesting drug candidates with potential applications in medicinal chemistry. ${ }^{8,9}$

In this perspective, the range of ring-opening reactions currently available for the synthesis of functionalised organoselenium and organotellurium compounds are reviewed. The methodologies covered include NRORs of three-, four-, five, and six-membered heterocycles with selenium and tellurium nucleophiles; particular attention is devoted to novel methodologies and to the use of "unconventional" reagents, developed over the last two decades.

\section{Ring opening of three-membered heterocycles}

\subsection{Synthesis of unsymmetric selenides and tellurides}

Several synthetic methodologies based on the ring opening reactions of three-membered heterocycles with selenium and tellurium nucleophiles have been reported. The reductive cleavage of the chalcogen-chalcogen bond of diselenides or ditellurides and the insertion of a chalcogen atom into a metal-carbon bond are arguably the most widely employed methods to generate nucleophilic metal organic selenolates and tellurolates. ${ }^{3 a, 10} \mathrm{~A}$ large variety of reagents have been used to reduce diselenides and ditellurides. Metal-hydrides, such as $\mathrm{NaBH}_{4}, \mathrm{NaH}, \mathrm{LiBEt}_{3} \mathrm{H}, \mathrm{LiAlH}_{4}$, are, along with sodium, the most commonly employed reducing agents (Scheme 1).

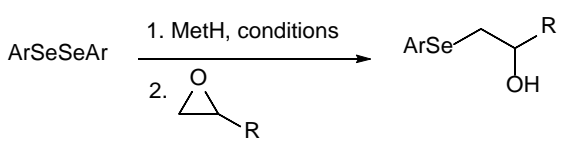

Scheme 1: General Metal hydride-promoted ring opening reaction of epoxides with diselenides 
An interesting example of generation of nucleophilic selenium and tellurium reagents under simple and mild conditions was reported by Lenardão and co-workers. ${ }^{11}$ Chalcogenated anions were in situ obtained from the corresponding diselenides $\mathbf{1}$, or ditellurides $\mathbf{2}$, and $\mathrm{NaBH}_{4} / \mathrm{Al}_{2} \mathrm{O}_{3}$ under solvent-free conditions, and then reacted with epoxides and lactones to provide $\beta$-chalcogenated alcohols $\mathbf{3}$, 4 and acids 5, 6 (Scheme 2).

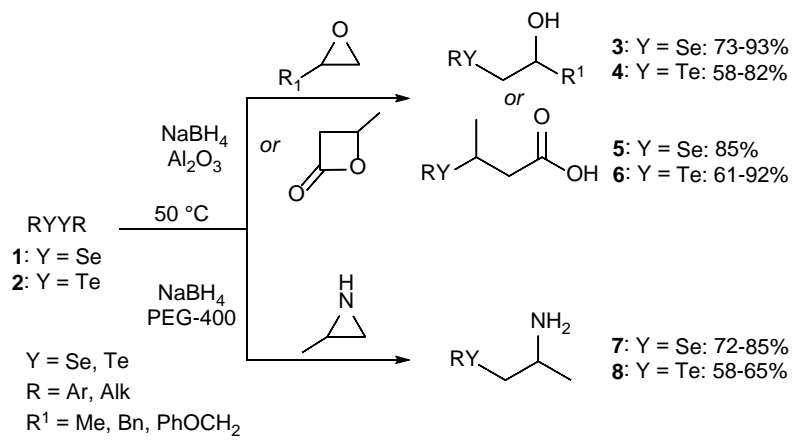

Scheme 2: Ring opening of three- and four-membered heterocycles with diorganyl dichalcogenides under $\mathrm{NaBH}_{4} / \mathrm{Al}_{2} \mathrm{O}_{3}$ or $\mathrm{NaBH}_{4} / \mathrm{PEG}$ 400 conditions.

Ring opening of unactivated 2-methylaziridine was more efficient with $\mathrm{NaBH}_{4} / \mathrm{PEG}-400$, leading to the $\beta$-seleno amine $\mathbf{7}$ in high yield, while lower yields were observed for the corresponding $\beta$-telluro derivative $\mathbf{8}$ (Scheme 2).

Recently, besides these "traditional" reagents a number of new methods have been emerged for the preparation of selenium and tellurium nucleophile species.

Chandrasekaran and co-workers reported a rongalite-promoted synthesis of $\beta$-hydroxy and $\beta$-amino selenides from diaryl diselenides and epoxides or aziridines (Scheme 3). ${ }^{12}$

$$
\begin{aligned}
& \underset{\mathrm{X}=\mathrm{O}, \mathrm{N}-\mathrm{Pg}}{\mathrm{ArSeSeAr}} \underset{\mathrm{R}^{1} / \mathrm{Ar}^{1}}{\stackrel{\mathrm{NaO}^{-}}{\mathrm{S} \mathrm{CO}_{3} \text { DMF, r.t. }}} \\
& \begin{array}{l}
3 \mathbf{3 a}, \mathrm{Ar}=\mathrm{Ph}, 90 \% \\
\mathbf{3 b}, \mathrm{R}=\left(\mathrm{CH}_{2}{ }_{2} \mathrm{CH}=\mathrm{CH}_{2}, 95 \%\right.
\end{array}
\end{aligned}
$$

Scheme 3: Selected examples from Chandrasekaran and coworkers' one pot rongalite promoted synthesis of $\beta$-hydroxy and $\beta$ amino selenides.

The methodology is stereospecific and regioselective; the NROR generally occurs on the less hindered carbon of the three- membered heterocycle. Mixture of regioisomers are formed when using 2-aryl-substituted (products 7e and 7e', Scheme 3 ) or some di- or tri-substituted substrates. The same procedure could also be applied to the reduction of diaryl disulfides, enabling to access $\beta$ functionalised sulfides, upon treatment of the in situ generated thiolate with epoxides or aziridines. However, although variously substituted epoxides and protected aziridines could be employed, the reaction is limited to diaryl diselenides and diaryl disulfides. A related rongalite promoted procedure, developed by $\mathrm{Xu}, \mathrm{Yu}$, and co-workers, allowed the regioselective synthesis of $\beta$-hydroxy tellurides by using diaryl ditellurides and monosubstituted epoxides. $^{13}$

Over the last two decades, a number of zinc-mediated ring opening procedures for the synthesis of functionalised selenides have been reported. Such procedures proceed through the reaction of epoxides and aziridines with zinc selenolates, generated by reductive cleavage of the corresponding diselenides. Movassagh and Shamsipoor reported that phenyl and benzyl selenolates can be easily generated from the corresponding diselenides upon treatment either with $\mathrm{Zn} / \mathrm{AlCl}_{3}$ or with zinc powder in $\mathrm{NaOH}$ aqueous solution. In situ reaction of the so generated zinc selenolates with epoxides afforded $\beta$-hydroxy selenides in high yields with good regioselectivity. ${ }^{14}$

Santi, Tiecco and co-workers reported an efficient zinc-mediated reduction of diselenides into the corresponding selenols, occurring in a biphasic system under acidic conditions (Scheme 4). ${ }^{15}$ Selenols generated under these conditions react in situ with epoxides, enabling the synthesis of $\beta$-hydroxy selenides. The NROR was found to be highly regioselective, generally occurring on the less substituted carbon of the oxirane. Notably, the nucleophilic attack occurred almost exclusively on the more hindered carbon (r.r. 19:1) when using styrene oxide. ${ }^{15}$

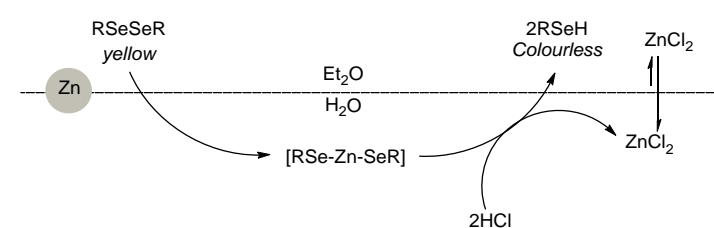

Scheme 4: Proposed mechanism for the zinc-mediated reduction of diselenides in a biphasic system.

This zinc-mediated methodology was also applied by Braga and coworkers to the synthesis of $\beta$-seleno amines through the ring opening of unprotected aziridines with diaryl and dialkyl diselenides (Scheme 5). ${ }^{16}$ The reaction was amenable to variously substituted diselenides, although lower yields were observed when using dialkyl diselenides and diaryl diselenides bearing electron-donating groups or ortho-substituted hindered rings. Notably, $\beta$-phenyltelluro amine 8 a was obtained from diphenyl ditelluride under the same reaction conditions.

Furthermore, Santi, Tiecco and co-workers found that (phenylselenenyl)zinc chloride, a bench-stable selenolate obtained from zinc and phenylselenyl chloride by oxidative insertion of $\mathrm{Zn}$ into the Se-Cl bond, could be efficiently employed in epoxides ring- 
opening reactions, occurring in water at room temperature with high yields and high regioselectivity (Scheme 6 , reaction $a){ }^{17}$

$$
\overbrace{\mathrm{X}=\mathrm{Re}, \mathrm{Te}}^{\stackrel{\mathrm{RXXR} / \mathrm{Zn}(0)}{\mathrm{HCl} / \mathrm{Et}_{2} \mathrm{O}}} \mathrm{RX}_{\mathrm{R}^{1}}^{\mathrm{RH}_{2}}
$$

\begin{tabular}{|c|c|c|}
\hline $\mathrm{NH}_{2}$ & $\mathrm{NH}_{2}$ & $\mathrm{NH}_{2}$ \\
\hline $7 \mathbf{g}, \mathrm{R}^{1}=\mathrm{Bn}, 77 \%$ & $7 \mathrm{j}, \mathrm{R}=2-\mathrm{Me}-\mathrm{C}_{6} \mathrm{H}_{4}, 35 \%$ & $8 a, 40 \%$ \\
\hline $7 \mathrm{~h}, \mathrm{R}^{1}={ }^{i} \mathrm{Pr}, 58 \%$ & $7 \mathrm{k}, \mathrm{R}=4-\mathrm{Me}-\mathrm{C}_{6} \mathrm{H}_{4}, 60 \%$ & \\
\hline \multirow[t]{3}{*}{$7 \mathrm{i}, \mathrm{R}^{1}={ }^{i} \mathrm{Bu}, 70 \%$} & $7 \mathrm{I}, \mathrm{R}=4-\mathrm{F}-\mathrm{C}_{6} \mathrm{H}_{4}, 83 \%$ & \\
\hline & $7 m, R=B n, 35 \%$ & \\
\hline & $7 \mathrm{n}, \mathrm{R}={ }^{n} \mathrm{Bu}, 35 \%$ & \\
\hline
\end{tabular}

Scheme 5: Selected examples of $\beta$-amino chalcogenides obtained through the ring opening reaction of unprotected aziridines in a biphasic system.

In a related study, Braga and co-workers reported an efficient NROR of protected and unprotected aziridines with (phenylselenenyl)zinc bromide in ionic liquids (Scheme 6, reaction $b$ ). ${ }^{18}$

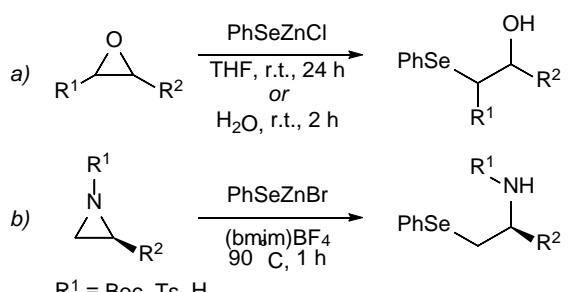

Scheme 6: Ring opening reactions of epoxides and aziridines with (phenylselenenyl)zinc halides.

Ionic liquids were also employed as reaction media and promoters in $\mathrm{CuO}$ nano particles-mediated ring opening reaction of aziridines with diorganyl diselenides, enabling the synthesis of chiral $\beta$-seleno amino derivatives. ${ }^{19}$

Procter and co-workers reported the ring opening reaction of epoxides with ytterbium(III) chalcogenolate complexes $\mathbf{9}$, conveniently prepared by insertion of ytterbium metal into the chalcogen-chalcogen bond of disulfides, diselenides, and ditellurides. ${ }^{20}$ Such lanthanide(III) chalcogenolate complexes are believed to play a dual role in the reaction with epoxides, both delivering the nucleophile species and activating the electrophile due to their Lewis acid behaviour. Furthermore, owing to the oxophilicity of lanthanides, the formation of ytterbium-oxygen bonds probably represents the driving force of the reaction. Variously alkyl-substituted epoxides were converted into the corresponding $\beta$-arylchalcogeno alcohols through this regio- and chemo-selective route (Scheme 7). On the other hand, a mixture of regioisomers was formed when styrene oxide was used. The scope of the reaction is limited to the use of diaryl dichalcogenides, as only poor yields were achieved employing alkyl analogues.

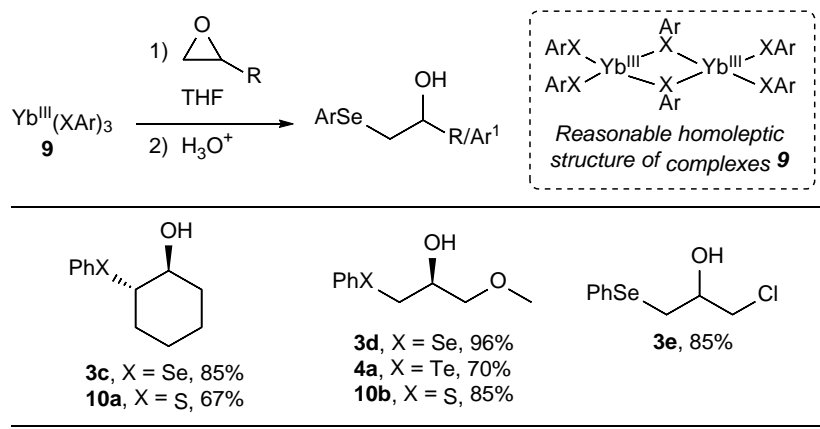

Scheme 7: Selected examples from Procter and co-workers' ring opening of epoxides with ytterbium(III) chalcogenolate complexes.

Chiral $\beta$-seleno amine derivatives were also synthesized under different conditions upon treatment of aziridines with indium(III)chalcogenolates, obtained from indium(I) chloride and diselenides. ${ }^{21}$ Indium(I)-compounds are able to generate the related In(III) derivatives through their oxidative insertion into suitable substrates (Scheme 8).

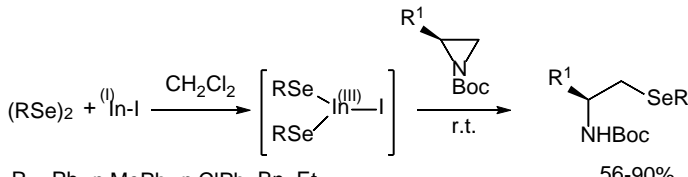

$$
\begin{aligned}
& \mathrm{R}=\mathrm{Ph}, p \text {-MePh, } p \text {-CIPh, Bn, Et }
\end{aligned}
$$$$
\mathrm{R}^{1}=\mathrm{Bn}, \mathrm{i}-\mathrm{Pr}, \mathrm{Me}, \mathrm{COOMe}
$$

Scheme 8: Indium-promoted synthesis of $\beta$-amino selenides.

Indium selenolate was faster in promoting the ring opening of aziridines with respect the selenolate anion generated with $\mathrm{NaBH}_{4} / \mathrm{EtOH}$. This could be ascribed to the coordination of the In(III)-complex through the oxygen of the $N$-Boc, promoting the nucleophilic attach of the selenium (Figure 2). In fact, when trityl was used as protecting group, no reaction was observed. ${ }^{21}$

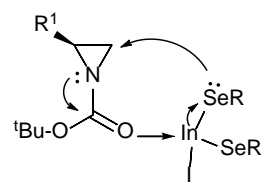

Figure 2: Proposed mechanism.

It is worthwhile to mention that using aziridine-2-carboxylates $\left(R^{1}=\right.$ $\left.\mathrm{CO}_{2} \mathrm{Me}\right)$ as starting material, a series of selenocysteine and selenotreonine derivatives with interesting structural diversity was straightforwardly prepared, without loss of optical purity.

Vargas and Comasseto reported the synthesis of chiral $\beta$ telluroamines via the NROR of $N$-Boc and $N$-Ts protected aziridines with lithium organotellurolates, in situ generated from elemental tellurium and organolithium compounds (Scheme 9). ${ }^{22}$ The authors found this method to be more efficient with respect to generating tellurium nucleophiles by reduction of ditellurides or by insertion of a tellurium into carbon-magnesium bonds. The same procedure could also be applied to the synthesis of related aminoselenides and aminosulfides. ${ }^{22}$ 


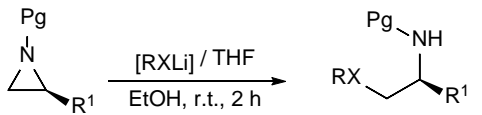

$\mathrm{X}=\mathrm{Se}, \mathrm{Te}$

$\mathbf{8 d}, \mathrm{R}^{1}=\mathrm{Bn}, 79 \%$
$\mathbf{8 c}, \mathrm{R}={ }^{n} \mathrm{Bu}, \mathrm{X}=\mathrm{Te}, 89 \%, \mathrm{X}=\mathrm{Te}, 80 \%$

Scheme 9: Selected examples from Vargas and Comasseto synthesis of $\beta$-amino organochalcogenides.

Ring-opening of epoxides was also achieved by treatment of diselenides in the presence of benzyl(triethyl)ammonium tetrathiomolibdate $\left(\left[\mathrm{BnNEt}_{3}\right]_{2} \mathrm{MoS}_{4}\right)$, which enabled cleavage of the Se-Se bond. ${ }^{23}$ The reaction was carried out also with precursors of diselenides, such as benzyl bromide (or benzyl alcohol) and KSeCN, which were treated with tetrathiomolibdate to in situ form the selenium anion, able to induce the ring opening of epoxides. $\beta$ Hydroxy selenides were so obtained under mild conditions through a one-pot tandem, multistep procedure (Scheme 10). ${ }^{23}$

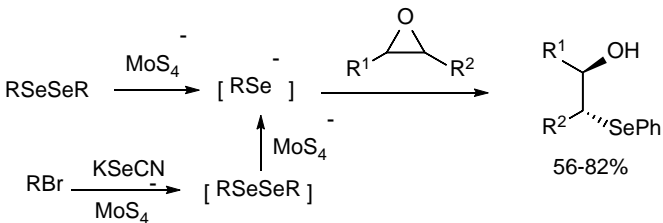

$$
\begin{aligned}
& \mathrm{R}=\mathrm{Ph}, \mathrm{Bn} \\
& \mathrm{R}^{1}=\mathrm{R}^{2}=-\left(\mathrm{CH}_{2}\right)_{4} ;-\left(\mathrm{CH}_{2}\right)_{3} \\
& \mathrm{R}^{1}=\mathrm{H}, \mathrm{R}^{2}=\mathrm{Me}
\end{aligned}
$$

Scheme 10: Tetrathiomolibdate-induced synthesis of $\beta$ phenylseleno alcohols.

Selenosilanes and tellurosilanes have also been employed as efficient reagents in ring opening reactions of strained heterocycles. Our interest in the chemistry of silyl chalcogenides ${ }^{24}$ led us to develop silicon-mediated procedures to access functionalised selenium- and tellurium-containing molecules under very mild conditions $\left(\mathrm{PhO}^{n} \mathrm{NBu}_{4}\right.$ catalysis). In this context, (phenylseleno)trimethylsilane $\mathbf{1 1}$ proved to be an effective selenium-transfer reagent, ${ }^{25}$ providing an alternative access to $\beta$ phenylseleno alcohols (Scheme 11). ${ }^{26}$ Interestingly, the reaction could also be performed in ionic liquids.

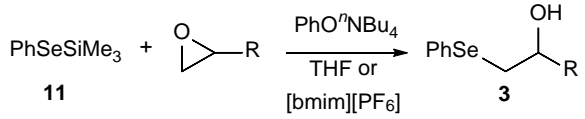

Scheme 11: Synthesis of $\beta$-phenylseleno alcohols from epoxides and $\mathrm{PhSeSiMe}_{3}$.

Tellurosilanes also behave as efficient reagents for the delivery of tellurium functionalities. Ogura and co-workers reported that (phenyltelluro)trimethylsilane $\mathbf{1 2}$ behaved as an efficient reagent for the transfer of the phenyltelluro moiety onto epoxides. ${ }^{27}$ Recently, in order to disclose novel ring-opening-based protocols for the synthesis of functionalised organotellurides, we extended the scope of the reactivity of silyl tellurides to aziridines and thiiranes (Schemes 12 and 13). ${ }^{28,29}$ The NRORs occurred with stereospecificity and excellent regioselectivity in the presence of TBAF.

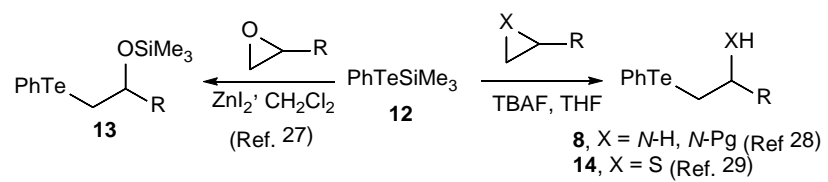

Scheme 12: Ring opening of epoxides, thiiranes, and aziridines with PhTeSiMe3.

Interestingly, besides $N$-Boc and $N$-Ts protected aziridines, the reactivity of arylchalcogeno silanes was successfully extended to $N$ $\mathrm{H}$ unactivated analogues to enable the synthesis of selenides, tellurides, and sulfides bearing free amino functionalities (Scheme 13). Taking into account that chalcogenoamines are valuable small molecules both in medicinal chemistry ${ }^{80,30}$ and in organic synthesis, $^{31}$ the development of a general and simple method for their synthesis appears highly desirable.

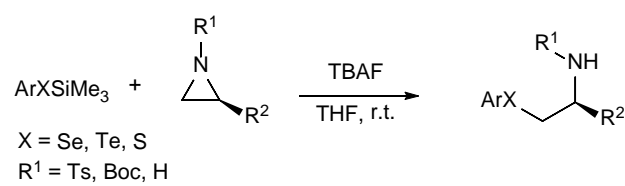

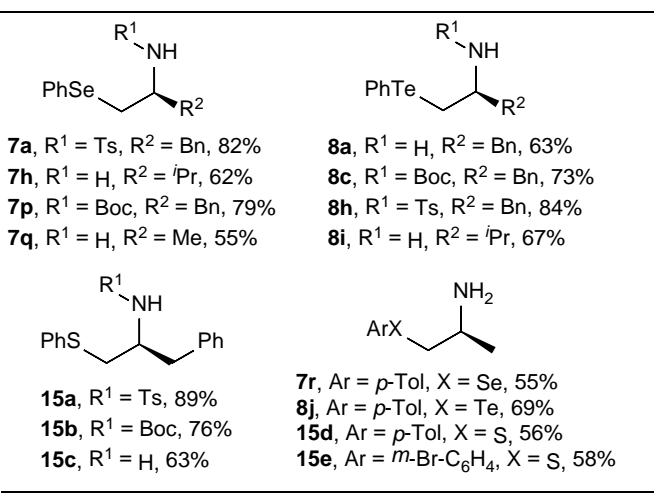

Scheme 13: Synthesis of $\beta$-arylchalcogeno amines through NRORs of aziridines with silyl chalcogenides.

Furthermore, besides silyl selenides, also organoselenides containing Se-B or Se-Sn bonds have been employed in ring opening reactions of epoxides. Nishiyama and Sonoda reported the synthesis of $\beta$-hydroxy selenides through the Lewis acid-promoted reaction of tributylstannyl selenide 16 with oxiranes (Scheme 14, reaction $a) .^{32}$ The formation of $\beta$-hydroxy selenides could also be accomplished by using selenoboranes 17 . However, as the formation of variable amounts of corresponding olefins was also observed depending on the substrate and the reaction conditions, 
this transformation proved to be less synthetically useful (Scheme 14 , reaction $b) .^{33}$

$$
\begin{aligned}
& \text { a) } \underset{16}{\mathrm{O}}>\mathrm{R}^{1}+\underset{\mathrm{PhSeSnBu}_{3}}{\stackrel{\mathrm{BF}_{3^{3}} \mathrm{Et}_{2} \mathrm{O}}{\mathrm{CH}_{2} \mathrm{Cl}_{2}}} \mathrm{PhSe} \underbrace{\stackrel{\mathrm{OH}}{\longrightarrow}}_{\mathrm{R}^{1}} \\
& \text { b) } \mathrm{R}^{1} \stackrel{\mathrm{O}}{\stackrel{\mathrm{B}\left(\mathrm{SeAr} / \mathrm{R}^{3}\right)_{3}}{17}} \mathrm{R}^{2} / \mathrm{ArSe} \underbrace{\mathrm{R}_{\mathrm{R}^{1}}}_{\mathrm{R}^{2}}+\mathrm{R}^{1} \gamma^{2} \mathrm{R}^{2}
\end{aligned}
$$

Scheme 14: Ring opening of epoxides with tributylstannyl selenide and selenoboranes.

The reactivity of silyl selenides with strained heterocycles have also been exploited for the synthesis of enantioenriched $\beta$-hydroxy- and $\beta$-amino- selenides through desymmetrization of meso-epoxides ${ }^{34}$ and meso-aziridines. ${ }^{35}$ Enantioenriched $\beta$-phenylseleno alcohols were achieved upon treatment of meso-epoxides with tertbutyl(dimethyl)(phenylseleno)silane in the presence of chiral salen(chromium) complexes (Scheme 15). The enantioselectivity of the process proved to be strongly influenced by the structure of the starting material. Rather good results were obtained in the synthesis of variously substituted stilbene derivatives (Scheme 15 $a, \mathbf{3 f}-\mathbf{h})$. On the other hand, the ring opening reaction of cyclic or alkyl epoxides generally gave lower enantioselectivities (Scheme 15, 3c). ${ }^{34}$

In a related work, enantioenriched $\beta$-phenylseleno amines $7 \mathbf{s}-\mathbf{u}$ were prepared by desymmetrization of meso- $\mathrm{N}$-acylaziridines employing (phenylseleno)silanes as nucleophiles and VAPOLderived phosphoric acid $(R)-\mathbf{1 8}$ as the catalyst (Scheme 15, $b$ ). The best results in terms of yield, enantioselectivity, and convenient reaction time, were obtained upon using a mixture of (phenylseleno)trimethylsilane 11 and benzeneselenol 19a as nucleophiles (Scheme 15, $b$ ). ${ }^{35}$

a) Desymmetrization of meso-epoxides with (phenylseleno)silanes

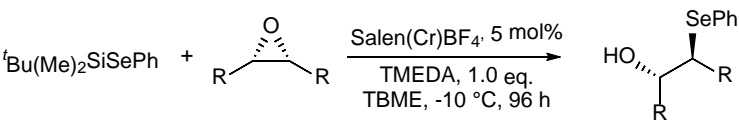

$$
\begin{array}{ll}
\text { Sf, } \mathrm{Ar}=\mathrm{Ph}, 92 \% \text {, e.r. } 96: 4 \\
\mathrm{Ar}, \mathrm{Ar}=p-\mathrm{F}-\mathrm{C}_{6} \mathrm{H}_{4}, 50 \% \text {, e.r. } 85: 15 \\
\mathbf{3 h}, \mathrm{Ar}=3-\mathrm{MeO}-\mathrm{C}_{6} \mathrm{H}_{4}, 50 \% \text {, e.r. } 75: 25
\end{array}
$$

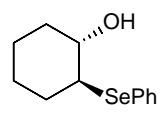

3c, $70 \%$, e.r. $67: 33$

b) Desymmetrization of meso-aziridines with (phenylseleno)silanes

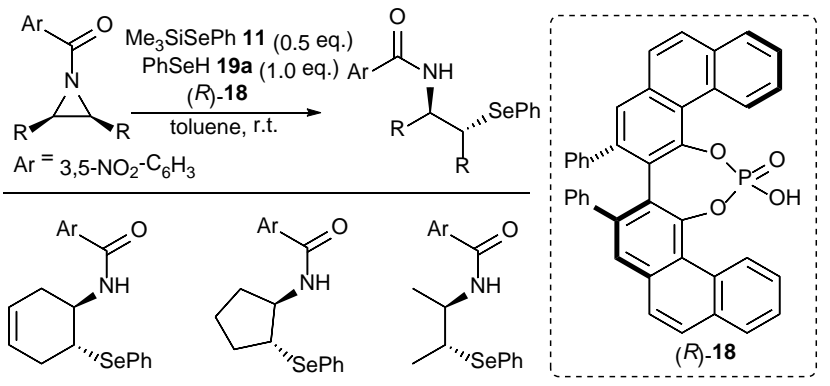

7s, $73 \%$, ee $95 \% \quad 7 t, 90 \%$, ee $96 \% \quad 7 u, 72 \%$, ee $92 \%$
Scheme 15: Desymmetrization of meso-epoxides and mesoaziridines with selenosilanes.

Selenols have also been used as nucleophiles in NRORs of threemembered heterocycles. Rao and co-workers developed a procedure for the synthesis of $\beta$-hydroxy selenides through the ring opening reaction of epoxides with benzeneselenol, occurring under mild conditions in the presence of $\beta$-cyclodextrin in water. ${ }^{36}$ Such a methodology enables the synthesis of variously substituted $\beta$ phenylseleno alcohols under supramolecular catalysis. The ring opening reaction proceeds with high regioselectivity via the formation of epoxide- $\beta-C D$ inclusion complexes, activating the oxirane and leading to the nucleophilic attack on the less hindered carbon of the strained heterocycle. ${ }^{36}$

Ionic liquid-promoted ring opening reactions of epoxides with aryl selenols have also been described. ${ }^{37}$ Benzeneselenol and 1naphthaleneselenol efficiently reacted with substituted epoxides in [bmim] $\mathrm{BF}_{4}$ to afford the corresponding $\beta$-arylseleno alcohols in good yield with moderate to good regioselectivity. ${ }^{1} \mathrm{H}$ NMR studies suggested that $\left[\mathrm{bmim} \mathrm{BF}_{4}\right.$ promotes the ring opening reaction by activating the epoxide through hydrogen bond interactions involving C2 proton of the imidazolium cation and the oxygen of the epoxide. $^{37}$

An heterometallic Ti-Ga-Salen catalysed enantioselective ring opening reaction of meso-epoxides with aryl selenols (benzeneselenol and 1-naphthaleneselenol) was also reported by Zhu and co-workers (Scheme 16). ${ }^{38}$ In the proposed reaction mechanism the two metal Lewis acids of $\mathbf{2 0}$ act synergistically, activating the epoxide and directing the nucleophilic attack of the selenol. This methodology enables the synthesis of optically active arylseleno alcohols in high yields and with generally good enantioselectivity. The best results were obtained when benzeneselenol was employed as nucleophile, being lower enantioselectivity levels observed when 1-naphthaleneselenol was used (Scheme 16). ${ }^{38}$

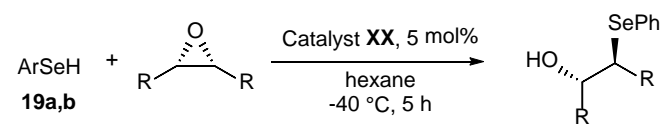

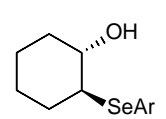

3c, $\mathrm{Ar}=\mathrm{Ph}, 94 \%$, ee $97 \%$ 3i, $\mathrm{Ar}=1-\mathrm{Naph}, 93 \%$, ee $78 \%$

$$
\int_{R}^{\text {SeAr }}
$$

3f, $\mathrm{Ar}=\mathrm{Ph}, \mathrm{R}=\mathrm{Ph}, 70 \%$, ee $72 \%$ 3j, $\mathrm{Ar}=\mathrm{Ph}, \mathrm{R}=\mathrm{Me}, 87 \%$, ee $87 \%$ 3k, $\mathrm{Ar}=1$-Naph, $\mathrm{R}=\mathrm{Me}, 73 \%$, ee $75 \%$ 31, $\mathrm{Ar}=1$-Naph, $\mathrm{R}=\mathrm{Ph}, 70 \%$, ee $55 \%$

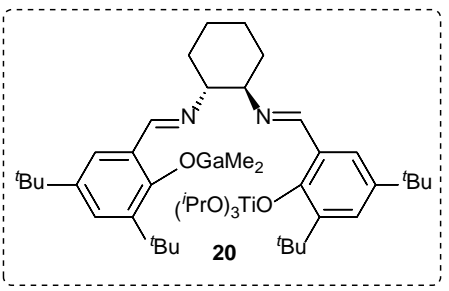


Scheme 16: Selected examples from Zhu and co-workers enantioselective ring opening reaction of meso-epoxides with ary selenols.

\subsection{Three-component ring-opening reactions}

Recently, alternative procedures based on three-component ringopening reactions of oxiranes with selenium powder and alkyl iodides, arylboronic acids, or terminal alkynes have also been reported.

$\mathrm{Wu}$, Liu, and co-workers developed a silver-catalysed one-pot procedure for the synthesis of $\beta$-hydroxy selenides from arylboronic acids $\mathbf{2 1}$, selenium powder and epoxides. ${ }^{39}$ This methodology allows the synthesis of a wide range of functionalised 2-arylseleno alcohols from readily available starting materials. $\beta$-Hydroxy selenides bearing substituted arylseleno or heteroarylseleno moieties could be achieved in moderate to good yields. However, although the ring opening arylselenation of epoxides could be performed with a wide range of arylboronic acids, the related alkenylselenation reaction proved to be less effective (compound 3q, Scheme 17).

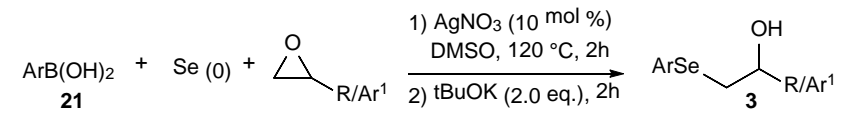$$
\text { (1) }
$$

$3 \mathrm{~m}, \mathrm{R}=2-\mathrm{Me}, 71 \%$
$3 \mathrm{n}, \mathrm{R}=3-\mathrm{Me}, 92 \%$

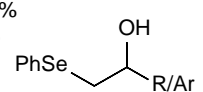

3a, $\mathrm{Ar}=\mathrm{Ph}, 90 \%$ $3 \mathrm{r}, \mathrm{Ar}=4-\mathrm{Cl}-\mathrm{C}_{6} \mathrm{H}_{4}, 54 \%$

3p, $48 \%$<smiles>OC(C[SeH])COc1ccc2c(c1)OCO2</smiles>

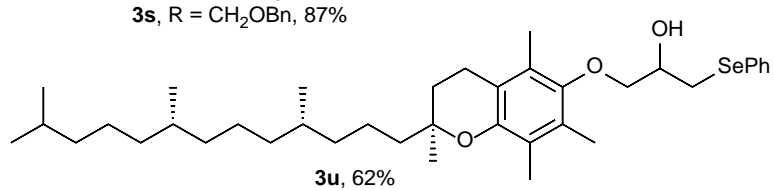

Scheme 17: Selected examples from Wu, Liu, and co-workers of ring opening reactions of epoxides with selenium powder and arylboronic acids.

This one-pot protocol was also applied to the synthesis of naturalproduct-derived selenides $\mathbf{3 t}$ and $\mathbf{3} \mathbf{u}$, from the corresponding sesamyl- and tocopheryl-glycidyl ethers and phenylboronic acid (Scheme 17).

The proposed mechanism for the three-component cascade reaction involves the base-promoted disproportionation of elemental selenium, followed by a silver-catalysed radical selenation of the organoboronic acid, and a final seleniummediated ring opening of the epoxide (Scheme 18). ${ }^{39}$

$\mathrm{Wu}$, Liu, and co-workers reported the synthesis of $\beta$-arylseleno alcohols via a copper catalysed three-component ring opening reaction of epoxides with selenium powder and aryl iodides. ${ }^{40}$ The methodology provides a straightforward access to a wide variety of hydroxy-substituted aryl-alkyl selenides with a good functional 3n, $R=3-M e, 92 \%$ 3s, $\mathrm{R}=\mathrm{CH}_{2} \mathrm{OBn}, 87 \%$ group tolerance (Scheme 19). The reaction is thought to proceed through a $\mathrm{S}_{\mathrm{N}} 2$-type NROR of the epoxide by the arylseleniumcopper intermediate, in situ formed from elemental selenium and the aryl iodide. ${ }^{40}$

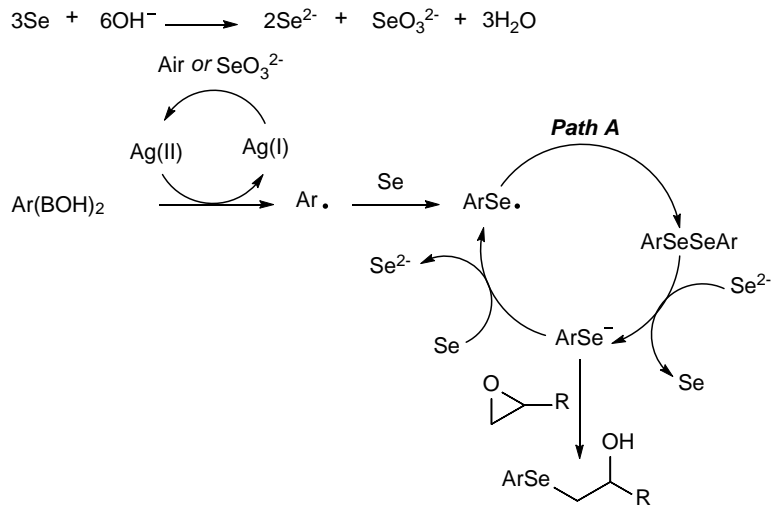

Scheme 18: Proposed reaction mechanism for the ring opening reactions of epoxides with $\mathrm{Se}(0)$ and arylboronic acids.

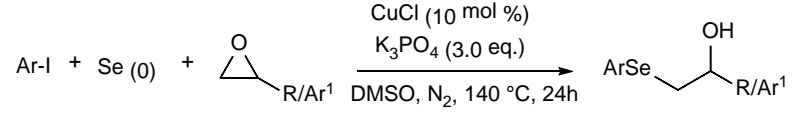

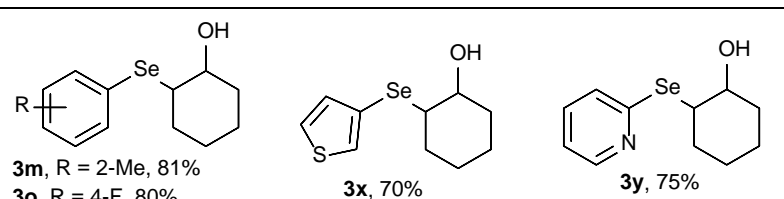

3o, $R=4-F, 80 \%$

$3 \mathrm{v}, \mathrm{R}=3-\mathrm{NO}_{2}, 65 \%$

$3 \mathrm{w}, \mathrm{R}=4-\mathrm{CO}_{2} \mathrm{Me}, 35 \%$

$$
\sim_{\mathrm{R} / \mathrm{Ar}}^{\mathrm{OH}}
$$

3a, $\mathrm{Ar}=\mathrm{Ph}, 76 \%$

$3 \mathrm{r}, \mathrm{Ar}=4-\mathrm{Cl}-\mathrm{C}_{6} \mathrm{H}_{4}, 75 \%$

3s, $\mathrm{R}=\mathrm{CH}_{2} \mathrm{OBn}, 85 \%$

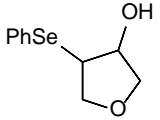

3aa, $81 \%$
Scheme 19: Selected examples from $\mathrm{Wu}$, Liu, and co-workers' ring opening reactions of epoxides with selenium powder and aryl iodides.

The same group also reported a metal-free synthesis of alkynyl alkyl selenides 3ab-3aj through the reaction of terminal alkynes, selenium, and epoxides. ${ }^{41}$ Such a methodology is amenable with a variety of terminal alkynes and epoxides, including a bioactive molecule such as pargyline (Scheme 20).

The reaction proceeds via a double C-Se formation and the proposed mechanism involves an initial disproportionation of elemental selenium to generate $\mathrm{Se}^{2-}$ which reacts with the epoxide to form an alkylselenolate anion. The latter is then oxidised to the corresponding diselenide which, upon reaction with the terminal alkyne in the presence of the base, affords the alkynyl alkyl selenide 
(Scheme 21). ${ }^{41}$ Notably, the first step is analogue to that proposed for the reaction of $\mathrm{Se}(0)$ with arylboronic acids (Scheme 18).

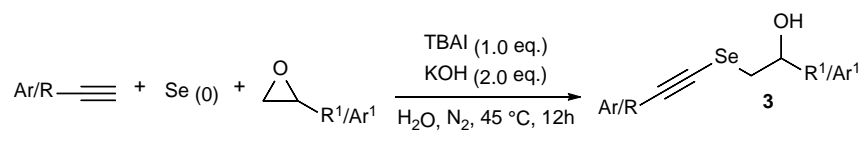

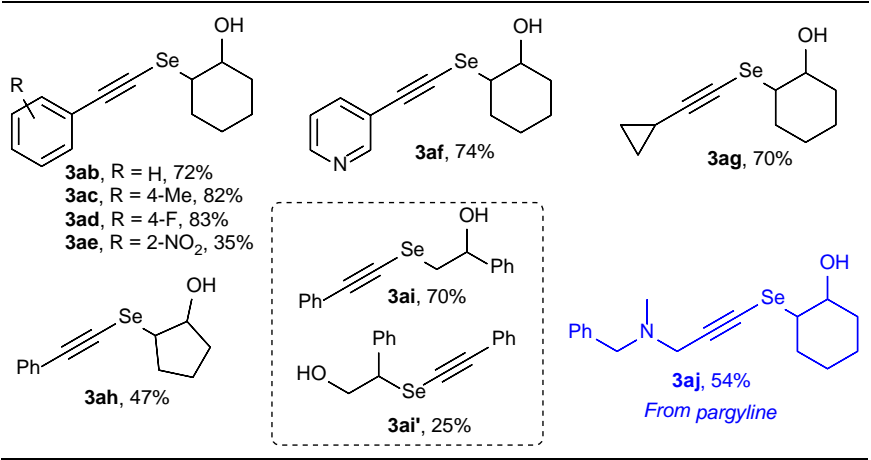

Scheme 20: Selected examples from $\mathrm{Wu}$, Liu, and co-workers of synthesis of hydroxy alkynyl alkyl selenides via three-component coupling of terminal alkynes, selenium, and epoxides.

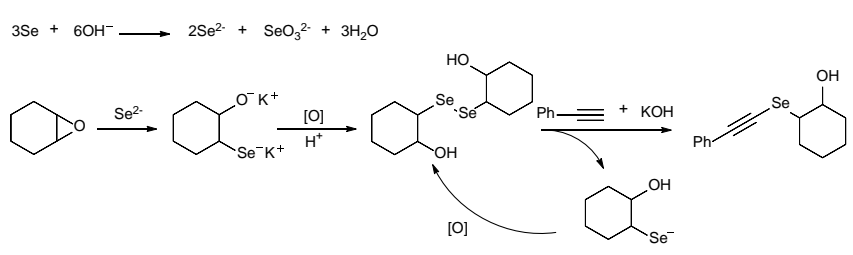

Scheme 21: Proposed reaction mechanism for the synthesis of hydroxy alkynyl alkyl selenides via three-component coupling of terminal alkynes, selenium, and epoxides.

\subsection{Synthetic applications of NRORs with chalcogens}

As stated in the introduction, NRORs of suitably substituted strained heterocycles with selenium and tellurium nucleophiles have been applied to the synthesis of heterocycles with different ring-size and biologically relevant organochalcogenides. For example, $\beta$-functionalised organochalcogenides have been employed by Engman and co-workers as valuable intermediates for the synthesis of tetrahydrofuran- and pyrrolidin-derivatives. ${ }^{42}$

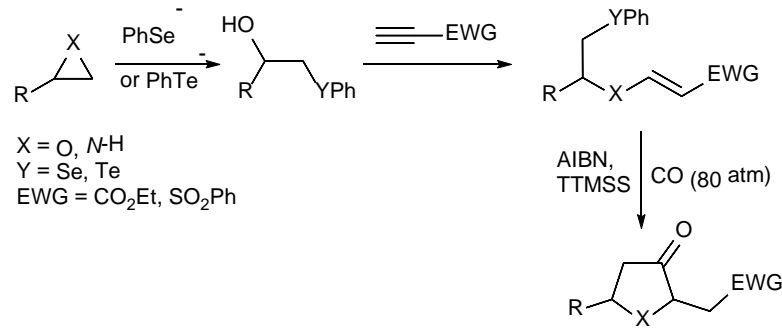

Scheme 22: Engman and co-workers' synthesis of 2,5-disubstituted tetrahydrofuran-3-ones and pyrrolidin-3-ones.

$\beta$-Hydroxyalkyl phenyl selenides, obtained through reaction of phenylselenide anion with epoxides, behaved as efficient Michael donors with ethyl propiolate to afford substituted alkyl vinyl ethers as pure $(E)$-isomers. These compounds were found to behave as radical precursors to give 2,5-disubstituted tetrahydrofuran-3-ones via carbonylation/reductive cyclization (Scheme 22). ${ }^{42}$

It is noteworthy that also phenyltellurolate was reacted with epoxides, and the obtained $\beta$-hydroxyalkyl phenyl tellurides afforded tetrahydrofurans-3-ones through the same route. Interestingly, this route was also extended to azirizidines, enabling the synthesis of pyrrolidin-3-ones (Scheme 22). ${ }^{43}$

An interesting example of the application of selenolates in NRORs is represented by the stereoselective formation of chiral $\beta$ phenylseleno amine, which was used as starting material to prepare enantiopure $\gamma$-aminocyclopentene derivatives (Scheme 23). These compounds represent important intermediates for the synthesis of carbocyclic nucleosides and $\gamma$-amino acid analogues. ${ }^{43}$

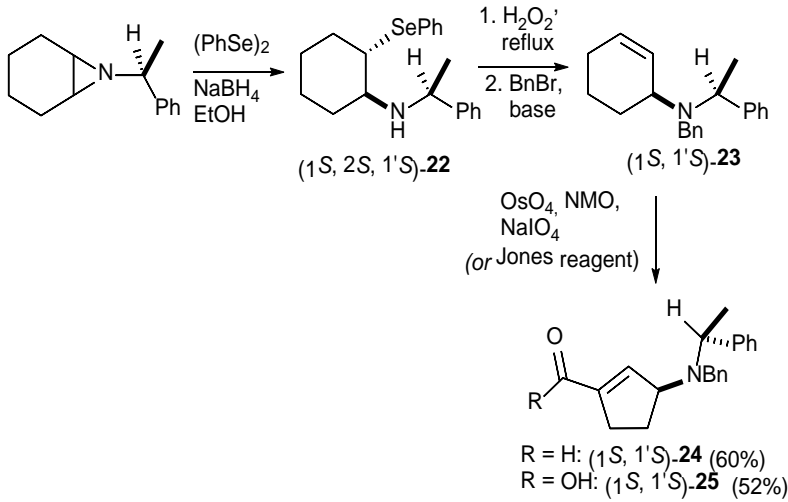

Scheme 23. Selective synthesis of enantiopure $\gamma$ aminocyclopentene derivatives 1 and 2 .

Ring opening of the chiral aziridine with phenyl senolate afforded the trans-aminoselenide $\left(1 S, 2 S, 1^{\prime} S\right)$-22 as major stereoisomer, which was transformed into the corresponding $\mathrm{N}$-benzyl-allyl amine $\left.1 S, 1^{\prime} S\right)-23$ by oxidation with hydrogen peroxide. This compound was then treated with $\mathrm{OsO}_{4} / \mathrm{NMO}, \mathrm{NaIO}_{4}$ to afford selectively the desired $\gamma$-aminocyclopentene aldehyde $(S)$-24 and the related $\gamma$ amino acid (S)-25 via an intramolecular selective aldol-condensation in the absence of an external base, behaving the amino group as internal base able to catalyse the ring closure. ${ }^{44}$

Also ring opening of a chiral epoxide (26) by diphenyldiselenide in the presence of $\mathrm{N}$-acetylcysteine represents one of the a key steps for the formal synthesis of the hepatite $B$ virus inhibitor entecavir (Scheme 24). Other key features of the procedure include a Sharpless asymmetric epoxidation, a Morita-Baylis-Hillma reaction and a Riley Selenium dioxide oxidation, leading in ten steps to entecavir. $^{44}$

Another example of chalcogen-promoted reductive-epoxide ring opening reaction was reported for the total synthesis of the enantiomer of the marine sponge diterpenoid (-)-nakamurol A. In this case, a suitable chiral epoxide was treated with tellurium in the presence of rongalite $\left(\mathrm{HOCH}_{2} \mathrm{SO}_{2} \mathrm{Na}\right){ }^{45}$ The so generated $\mathrm{Te}^{2-}$ induces a $\mathrm{S}_{\mathrm{N}}$ upon the Ts-group followed by opening of the epoxide, 
with the formation of an epi-telluride, which loses $\mathrm{Te}^{0}$ through a stereocontrolled process, leading to ent-nakamurol A (Scheme 25).

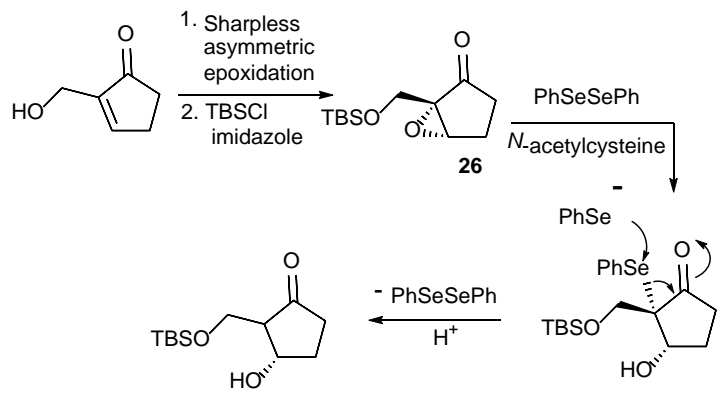

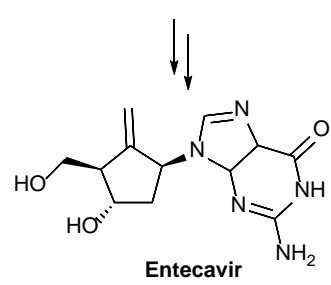

Scheme 24: Synthesis of Entecavir.

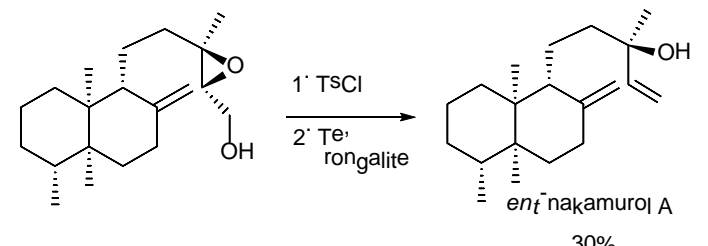

Scheme 25: Synthesis of ent-nakamurol A

Ring opening of chiral epoxides bearing an oxygenated aliphatic chain by phenylselenolate was used to obtain differently substituted hydroxy selenides as precursors of cis-disubstituted tetrahydrofurans $\mathbf{2 7}$ via 5-endo cyclization of seleniranium ions (Scheme 26). ${ }^{46}$

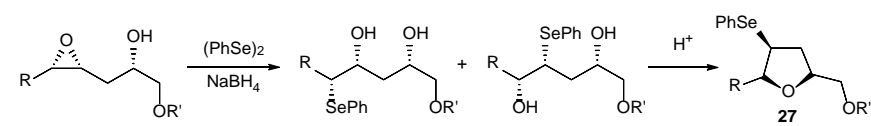

Scheme 26: Synthesis of selenium-containing tetrahydrofurans.

A particular example of intramolecular cyclization of selenated $\delta$ lactones was induced by silica gel during their purification, leading to the $\gamma$-lactone $\mathbf{2 8}$ with high d.r. The acid conditions caused the protonation of $\delta$-lactones $\mathbf{2 9}$ followed by intramolecular Se-attack at $C(6)$ and subsequent ring opening, with the formation of the intermediate seleniranium ion $\mathbf{3 0}$, which then cyclized to yield $\mathbf{2 8}$ (Scheme 27). ${ }^{47}$

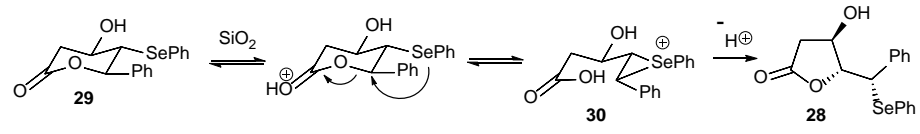

Scheme 27: Synthesis of selenium-containing lactones.

Selenosteroids, containing a combination of oxysterols and selenium, could have a great potential for biological applications as pro-oxidant biomolecules. Therefore, ring opening of the epoxide of cholesterol by treatment with diselenides under $\mathrm{NaBH}_{4}$ or $\mathrm{Zn}(0) / \mathrm{HCl}$ conditions represented an interesting way to introduce stereoselectively selenium in the steroidal nucleus, through an antiepoxide ring-opening and formation of trans-hydroxy selenides $\mathbf{3 1}$ (Scheme 28). ${ }^{48}$

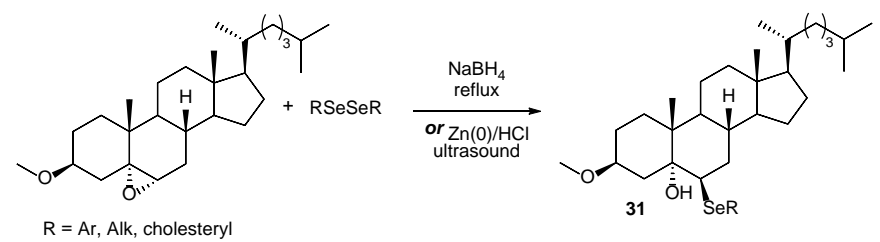

Scheme 28: Synthesis of selenosteroids.

Similarly, treatment of the epoxide with dilithium diselenide $\left(\mathrm{Li}_{2} \mathrm{Se}_{2}\right)$, led to the $\beta$-hydroxy cholesterol diselenide.

Furthermore, a methodology that combines sugar and steroid scaffolds linked by a selenium atom was developed using a sterereoselective nucleophilic substitution of modified human steroids, as cholesterol and pregnenolone, and plant steroids (stigmasterol and sitosterol), with carbohydrate diselenide derivatives (Scheme 29). The substitution of oxygen by sulfur or selenium in conjugate linkage of biomolecules is frequently used to modify their properties. Cholesterol-derived selenoglycoconjugates 32 were prepared by the ring-opening of the steroid-epoxide with selenium-sugar nucleophiles (Se-pyranosides and furanosides), generated in situ by reductive cleavage of the diselenide bond with $\mathrm{NaBH}_{4}$ (Scheme 29). ${ }^{49}$

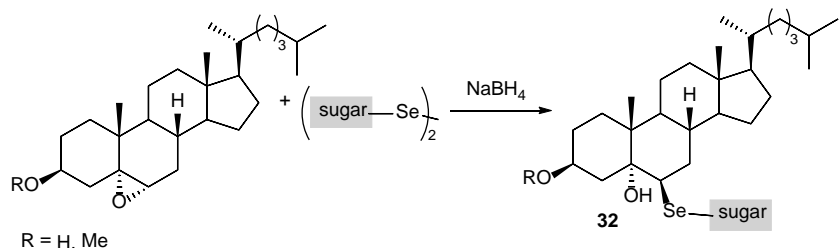

sugar $=$ D-galactose, D-xylose, D-ribose, D-mannose

Scheme 29: Synthesis of steroidal selenoglycoconjugates 32 .

Steroidal selenoglycoconjugates $\mathbf{3 2}$ were obtained as single isomers through regioselective epoxide opening by sugar-selenolates.

Another biologically relevant class of selenated compounds is represented by non-natural amino acids derivatives. To access these molecules, $\beta$-phenylseleno amines, prepared from $N$-Boc aziridines were reacted with anhydrides of $N$-protected amino acids to furnish non-natural selenium-containing amino acid derivatives and peptides (Scheme 30). ${ }^{50}$ 


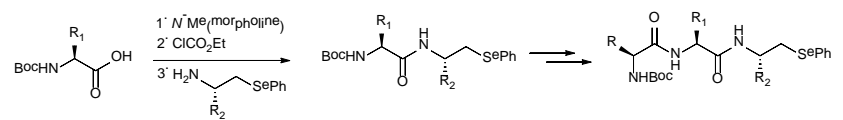

Scheme 30: Synthesis of non-natural selenium-containing amino acid derivatives.

In this context, thiiranes have been scarcely studied with respect to their oxygen- and nitrogen-containing analogues. Punniyamurthy and co-workers reported the construction of chalcogen-containing heterocycles exploiting the reactivity of thiiranes with isoselenocyanates. $^{51}$ The formation of 2-imino-thiaselenolanes 33 and 33' proceeded through a metal free [3+2] cycloaddition under $\mathrm{BF}_{2} \mathrm{OTf} \mathrm{OEt}_{2}$ catalysis (Scheme 31). Analogously, isothiocyantes led to the corresponding 2-imino-dithiolanes.

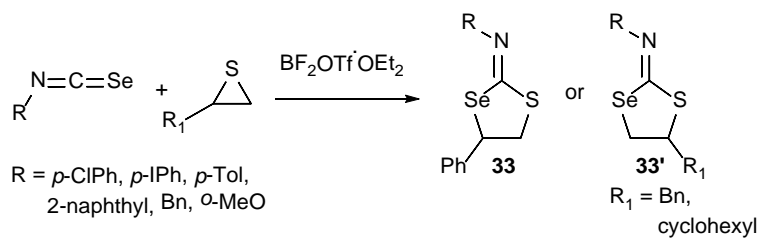

Scheme 31: Reaction of thiiranes with isoselenocyanates.

The regioselectivity was depending on the nature of the thiirane. Phenyl-substituted substrates underwent attack by the nucleophile at the benzylic carbon under electronic control, leading to compound 33. Conversely, when alkyl thiiranes were employed, the attack occurred at the less hindered side for steric effects yielding regioisomer 33'.

The proposed catalytic mechanism foresees a coordination of the hard Lewis acid with the hard base ( $\mathrm{N}$ atom), affording the intermediate $\mathbf{3 4}$, which reacts with the thiirane via regioselective nucleophilic ring opening at positions 2 or 3, followed by chemoselective [3+2] cyclization to afford the target compounds (Scheme 32). ${ }^{51}$

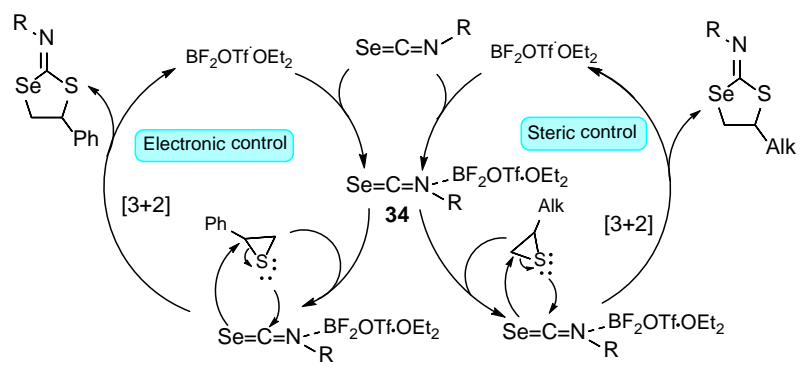

Scheme 32: Proposed reaction mechanism for the formation of 2 imino-thiaselenolanes.

2.4 Synthesis of functionalised dialkyl selenides, diselenides, and selenols

Although numerous ring-opening routes are available to produce aryl-alkyl selenides, the synthesis of functionalised dialkyl selenides and diselenides is significantly less developed. Commonly used procedures towards these compounds employ metal dichalcogenides or chalcogenides, such as lithium and sodium derivatives, normally generated in the presence of metal hydrides. Braga and co-workers reported the synthesis of enantioenriched $\beta$ amino diselenides through the NROR of $N$-Boc protected aziridines with $\mathrm{Li}_{2} \mathrm{Se}_{2}$, in situ generated upon treatment of elemental selenium with $\mathrm{LiBEt}_{3} \mathrm{H}$ (Scheme 33). The so obtained bi-dentate systems have been applied in asymmetric catalysis as chiral ligands for the enantioselective addition of diethylzinc to aldehydes (Scheme 33). ${ }^{52}$

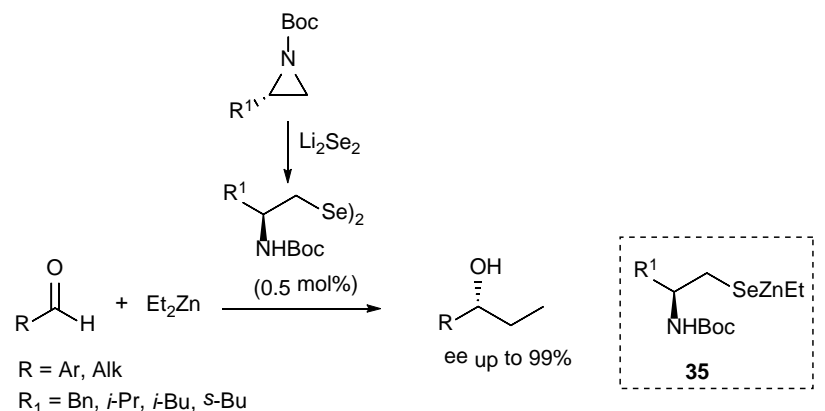

Scheme 33: Synthesis of enantioenriched $\beta$-amino diselenides and their application as catalysts for the enantioselective addition of diethylzinc to aldehydes.

Alcohols were obtained in high yields with aromatic aldehydes, while lower yields were achieved with aliphatic aldehydes. In all cases the alcohol with $(R)$-configuration was the predominant isomer observed. From the mechanicistic point of view, zincselenolate $\mathbf{3 5}$ was proposed as the active catalyst of the reaction. ${ }^{52}$ The harsh reaction conditions represent the main drawback of the metal hydrides-based methodologies, therefore limiting their application to substrates which does not contain labile or basesensitive moieties.

In this scenario, we recently addressed this issue by disclosing convenient alternative mild silicon-mediated routes towards functionalised dialkyl chalcogenides and dichalcogenides. Particularly, bis(trimethylsilyl)selenide $36 \quad$ - $\quad$ or hexamethyldisilaselenane ( $\mathrm{HMDSS}),\left(\mathrm{Me}_{3} \mathrm{Si}\right)_{2} \mathrm{Se}$ - behaved as a very versatile selenium transfer reagent, enabling the synthesis of different classes of organoselenium compounds upon reaction with strained heterocycles in the presence of catalytic amount of fluoride or phenolate anions. Epoxides, aziridines, and thiiranes could be selectively converted into the corresponding $\beta$-hydroxy-, $\beta$-amino-, and $\beta$-mercapto- selenides (37-39) or diselenides (40-42) just tuning the amount of $\left(\mathrm{Me}_{3} \mathrm{Si}\right)_{2} \mathrm{Se}^{53}$ Indeed, selenides were the exclusive reaction products observed when using an excess of the electrophile (ca. 2.0 eq.) with respect to the selenosilane. On the other hand, diselenides were solely formed upon using an excess of HMDSS (Scheme 34). Notably, these silicon-mediated NROR occurred stereospecifically with excellent regioselectivity, being observed only the product arising from the nucleophilic attack onto the less hindered carbon atom of the strained heterocycle. 


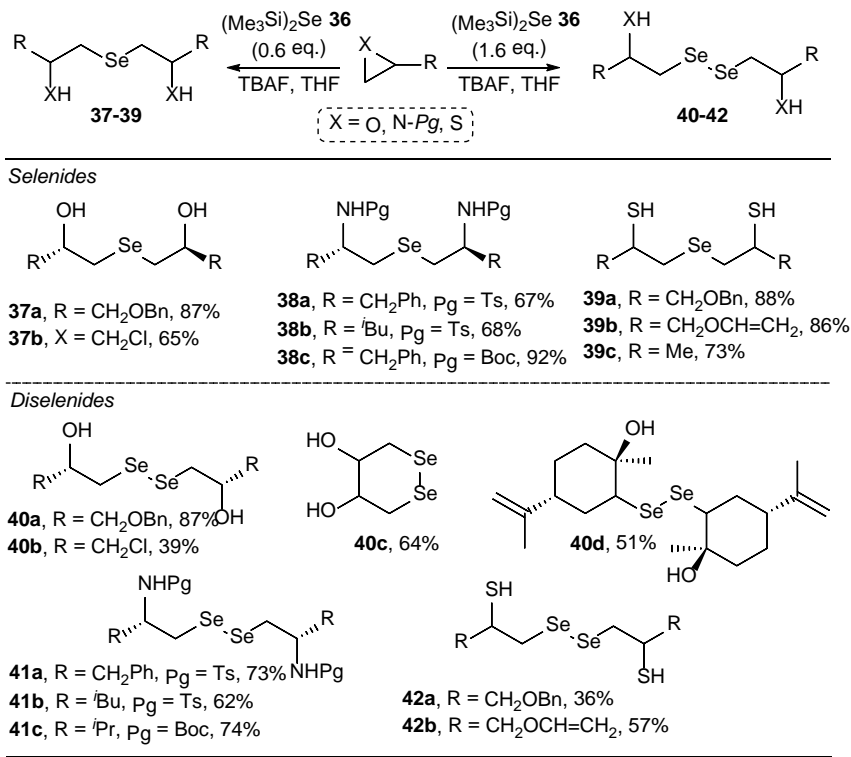

Scheme 34: Selective synthesis of selenides and diselenides through the reactivity of $\left(\mathrm{Me}_{3} \mathrm{Si}\right)_{2} \mathrm{Se}$ with epoxides, aziridines, and thiiranes (selected examples).

Furthermore, the reactivity of $\left(\mathrm{Me}_{3} \mathrm{Si}\right)_{2} \mathrm{Se} 36$ with thiiranes also enabled the synthesis of 3,7-disubstituted dithiaselenepanes 43, reasonably arising from the oxidative ring closure of the bis-silylsulfide intermediate. Notably, this procedure also allowed the synthesis of trithiepanes $\mathbf{4 4}$ when $\left(\mathrm{Me}_{3} \mathrm{Si}\right)_{2} \mathrm{~S}$, the sulfurated analogue of HMDSS, was employed (Scheme 35). ${ }^{54}$

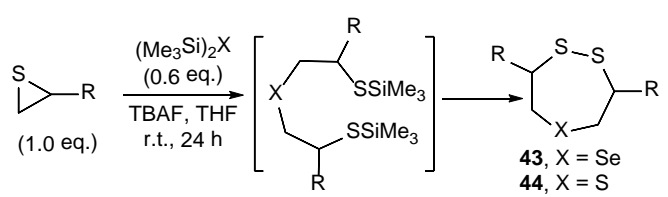

Scheme 35: Synthesis of dithiaselepanes and trithiepanes from thiiranes and silyl chalcogenides.

A plausible mechanism for these silicon-mediated ring opening reactions (Scheme 36) involves the formation of silicon hypervalent species. In the first step, a pentacoordinate species $\mathbf{4 5}$ is formed by coordination of the fluoride ion with the silicon atom of $\left(\mathrm{Me}_{3} \mathrm{Si}\right)_{2} \mathrm{Se}$ 36.

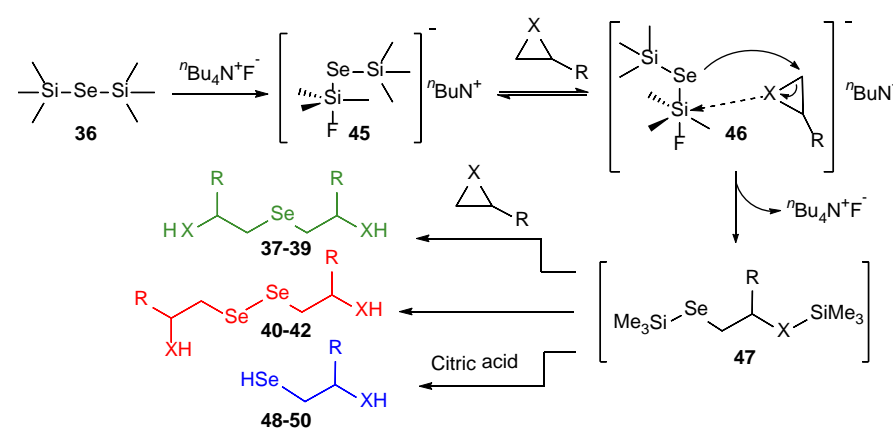

Scheme 36: Reaction mechanism fluoride ion-induced ring opening reaction of strained heterocycles with $\left(\mathrm{Me}_{3} \mathrm{Si}\right)_{2} \mathrm{Se}$.
The hexacoordinate silicon intermediate 46, formed upon interaction of $\mathrm{Si}$ with the heteroatom of the strained heterocycle, undergoes regioselective nucleophilic attack of Se leading to the key intermediate 47. TBAF is also released in this step, thus accounting for the catalytic role played in such reactions. The fate of the intermediate $\mathbf{4 7}$ depends on both the stoichiometry of the reaction and the reaction conditions. Indeed, selenides 37-39 and diselenides $\mathbf{4 0 - 4 2}$ can be selectively achieved as stated above.

Notably, we recently found that, owing to the very mild reaction conditions of this novel silicon-mediated route, $\beta$-hydroxy-, $\beta$ amino-, and $\beta$-mercapto-selenols 48-50 could be efficiently achieved from the corresponding three-membered heterocycles and HMDSS under strictly controlled reaction conditions, using citric acid as the proton source (Scheme 37). ${ }^{55}$

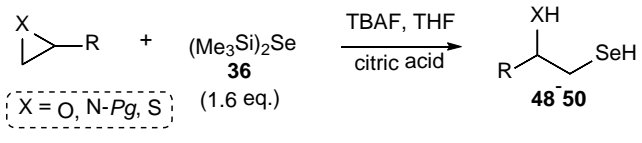

$$
\begin{aligned}
& \text { 48a, } \mathrm{R}=\mathrm{CH}_{2} \mathrm{OBn}, 86 \% \\
& \text { 48b, } \mathrm{R}=\mathrm{CH}_{2} \mathrm{OPMB}, 78 \% \quad \text { (S) }-48 \mathbf{a}, 84 \% \\
& \text { 48c, } \mathrm{X}=\mathrm{CH}_{2} \mathrm{Cl}, 65 \% \\
& \text { SeH } \\
& \text { 49a, } \mathrm{R}=\mathrm{CH}_{2} \mathrm{Ph}, \mathrm{Pg}=\mathrm{Ts}, 82 \% \\
& \text { 49b, } \mathrm{R}={ }^{i} \mathrm{Bu}, \mathrm{Pg}=\mathrm{T} \text { s, } 76 \% \\
& \text { 49c, } \mathrm{R}={ }^{i} \mathrm{Pr}, \mathrm{Pg}=\mathrm{Boc}, 84 \% \\
& \overbrace{\mathrm{R}}^{\mathrm{SH}} \mathrm{SeH}
\end{aligned}
$$

Scheme 37: Selected examples of synthesis of $\beta$-functionalised selenols through the reactivity of $\left(\mathrm{Me}_{3} \mathrm{Si}\right)_{2} \mathrm{Se}$ with epoxides, aziridines, and thiiranes.

The synthesised $\beta$-functionalised alkyl selenols exhibited an unexpected stability and could be easily handled and employed in further unexplored transformations. Indeed, owing to the unique features of the selenol moiety, selenols can be selectively functionalised with a wide array of electrophiles under very mild conditions, enabling the synthesis of a plethora of organoselenium compounds ${ }^{55-58}$ 51-58 which would have been difficult to access through other methodologies (Scheme 38).

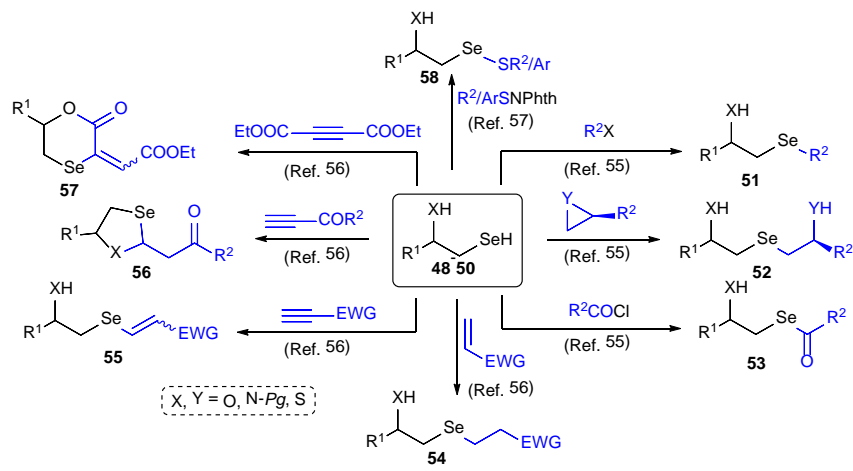

Scheme 38: Functionalization of selenols towards cyclic and acyclic organoselenium compounds. 
Recently, we also evaluated the reactivity of $\left(\mathrm{Me}_{3} \mathrm{Si}\right)_{2} \mathrm{Te}$ with strained heterocycles. However, its instability prompted us to employ a different Te-nucleophile such as $\mathrm{Li}_{2} \mathrm{Te}$, in situ generated by reduction of elemental tellurium with $\mathrm{LiEt}_{3} \mathrm{BH}$. The reaction of epoxides and aziridines with $\mathrm{Li}_{2} \mathrm{Te}$ enabled the first synthesis of $\beta$ hydroxy- and $\beta$-amino- dialkyl tellurides 59 and 60; on the other hand, under these conditions, thiiranes were directly converted into the corresponding 3,7-disubstituted 1,2,5-dithiatellurepanes 61 (Scheme 39). ${ }^{29}$

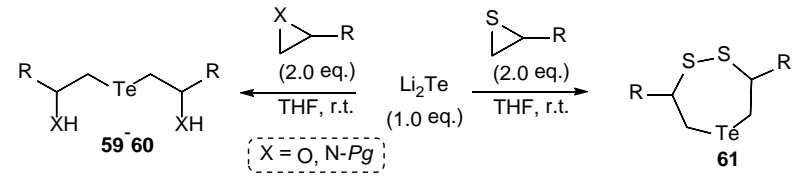

$$
\begin{aligned}
& \mathrm{C}_{\mathrm{R}}^{\mathrm{OH}} \mathrm{C}_{\mathrm{R}}^{\mathrm{OH}}
\end{aligned}
$$

Scheme 39: Synthesis of $\beta$-functionalised tellurides from threemembered heterocycles.

The good functional group tolerance of these procedures allows their application to the synthesis of complex and densely functionalised systems. These structural features are often one of the key criteria to meet in order to develop new effective catalysts and drug candidates. For example, very recently we have applied ring-opening procedures to the synthesis of novel chalcogencontaining carbonic anhydrase modulators ${ }^{80,30,59}$ and catalytic or chain-breaking antioxidants. ${ }^{56,60}$

As alternative method to the use of $\left(\mathrm{Me}_{3} \mathrm{Si}\right)_{2} \mathrm{Se}$ or $\mathrm{Se}(0) / \mathrm{LiBEt}_{3} \mathrm{H}$ conditions, $\beta$-amino diselenides could also be achieved relying on the reactivity of tetraethylammonium tetraselenotungstate $\mathbf{6 2}$ with aziridines. Chandrasekaran and co-workers developed a regioselective and stereospecific procedure for the efficient conversion of monosubstituted and disubstituted $\mathrm{N}$-tosyl activated aziridines into the corresponding diselenides (Scheme 40). ${ }^{61}$ However, this route could not be applied to the ring opening of $\mathrm{NH}$ unactivated aziridines, which proved to be unreactive upon treatment with selenotungstate $\mathbf{6 2}$. The proposed mechanism involves the formation of a key intermediate $\mathbf{6 3}$ which affords the diselenide through an internal redox process (Scheme 40 ).

Tetraethylammonium tetraselenotungstate $\mathbf{6 2}$ behaved as a very efficient selenium transfer reagent, enabling also the synthesis of conformationally locked bridged bicyclic diselenides 64 from the corresponding substituted cis-aziridino epoxides (Scheme 41). ${ }^{61 b, 62}$ Interestingly, whilst the aziridine ring-opening always occurs at the more hindered carbon atom, the regiochemistry of the selenium nucleophilic attack on the epoxide strongly depends on the structure of the substrate and may take place at either the less substituted or at the more substituted carbon atom of the oxirane (structures 64f and 64f', Scheme 41). ${ }^{61 b, 62}$

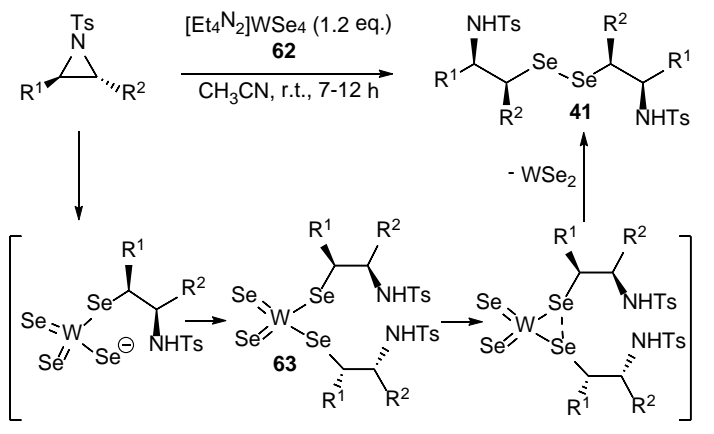

$\mathbf{4 1 b}, \mathrm{R}^{1}={ }^{i} \mathrm{Bu}, 80 \%$
$\mathbf{4 1 d}, \mathrm{R}^{1}=\mathrm{Me}, 74 \%$
$\mathbf{4 1 e}, \mathrm{R}^{1}={ }^{i} \mathrm{Pr}, 82 \%$

Scheme 40: Proposed reaction mechanism and selected examples from Chandrasekaran and co-workers' ring opening of aziridines with tetraethylammonium tetraselenotungstate.

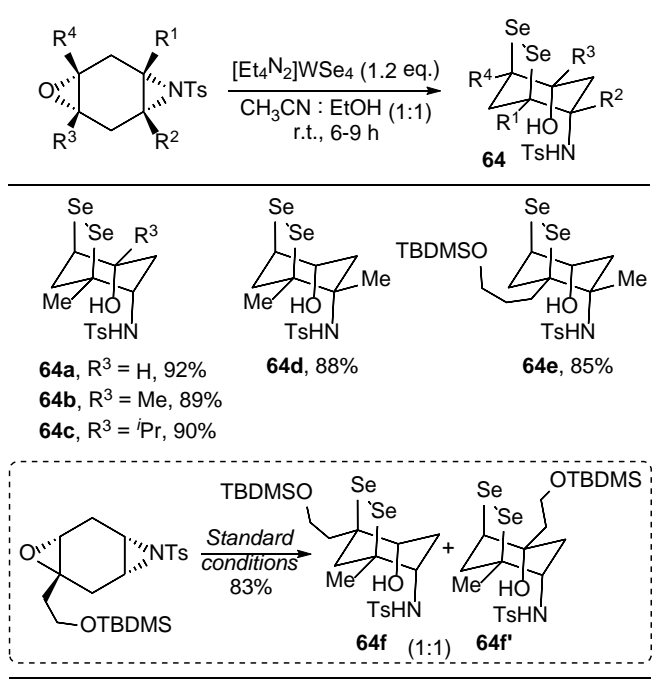

Scheme 41: Selected examples from Chandrasekaran and coworkers' ring opening of cis-aziridino-epoxides with tetraethylammonium tetraselenotungstate.

Furthermore, the functionalised cyclic diselenide 65 was also obtained exploiting the reactivity of tetraethylammonium tetraselenotungstate with the bis-aziridine 66 (Scheme 42). ${ }^{61 b, 62}$

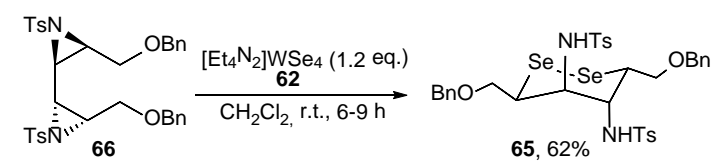

Scheme 42: Synthesis of cyclic diselenide 65.

Chandrasekaran and co-workers also reported an unusual selenaaza-Payne-type rearrangement, occurring upon treatment of $(\mathrm{N}$ - 
tosylaziridinyl)methyl tosylates $\mathbf{6 7}$ with tetraethylammonium tetraselenotungstate $\mathbf{6 2} .^{61 b, 63}$ The reaction proceeds via the formation of a selenirane intermediate which undergoes selenium elimination, leading to the formation of allyl amine derivatives $\mathbf{6 8}$ with good regio- and stereo-selectivity. Intriguingly, for most of the substrates employed in the study, the first step of the proposed mechanism is represented by the regioselective nucleophilic attack of the selenotungstate onto the aziridine. The displacement of the OTs group, which generally occurs first in the well-studied Payne, aza-Payne, thia-Payne, follows the NROR and leads to the formation of products 68 and 69 reported in the Scheme 43 . The overall result of this rearrangement is a nitrogen migration from $C(2), C(3)$ to $C(1)$ carbon (Scheme 43). Interestingly, while aziridinemethanoltosylates 67a were exclusively converted into the corresponding allyl amines 68a with high yields and excellent regioselectivity, transaziridinemethanoltosylates trans-67b led to the formation of a mixture of the corresponding allyl amine trans-68b (major product) and the cyclic diselenide trans-69 (minor product). Furthermore, reaction of cis-aziridines cis-67b with selenotungstate $\mathbf{6 2}$ furnished a mixture of regioisomers of allyl amines cis-68b and $\mathbf{6 8} \mathbf{b}^{\prime}$, together with the cyclic diselenide cis-69. ${ }^{61 b, 63}$
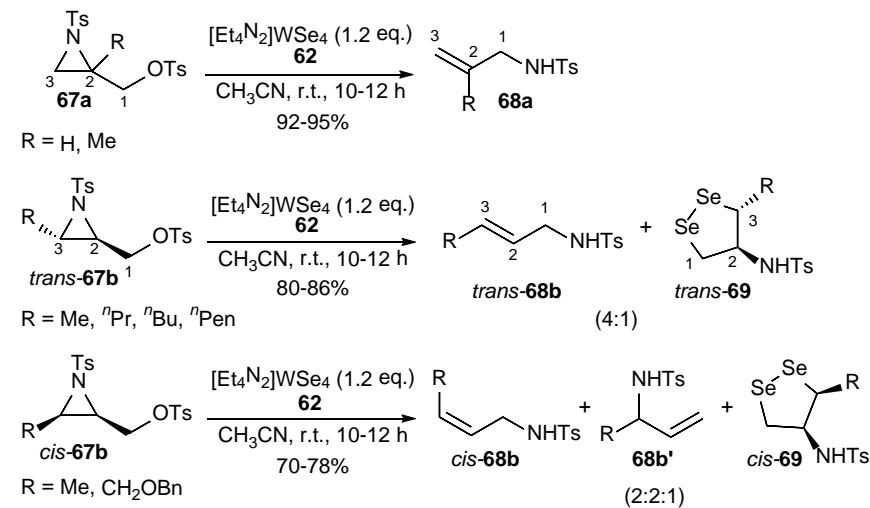

Scheme 43: Selenotungstate-mediated selena-aza-Payne-type rearrangement of azyridinylmethyl tosilates.

A simple and high yielding telluride-triggered procedure for the conversion of aziridinemethanoltosylates into racemic and nonracemic allyl amines has been reported by Dittmer and co-workers (Scheme 44$).{ }^{64}$ In a related procedure, $\mathrm{N}$-trityl- or $\mathrm{N}$-benzhydrylprotected allyl amines were obtained upon treatment of the corresponding aziridinemethanol sulfonate esters with sodium telluride, in situ generated from elemental tellurium and $\mathrm{NaBH}_{4}$. Notably, the formed $\mathrm{Te}(0)$ can be recovered and reused, thus removing the need of its disposal. ${ }^{65}$

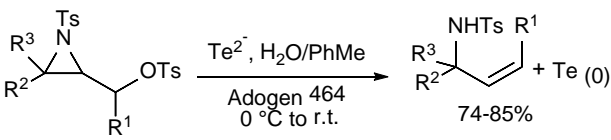

$$
\begin{aligned}
& R^{1,} R^{2,} R^{3}=H, A l k
\end{aligned}
$$

Scheme 44: Telluride-promoted synthesis of allyl amines from aziridinemethanol derivatives.
Dittmer and co-workers also developed tellurium-mediated methodologies for the synthesis of allylic alcohols exploiting the reactivity of telluride ions, generated upon treatment of elemental tellurium with various reducing agents, with sulfonate esters of oxiranemethanols. The regiochemistry of these reactions is strongly influenced by electronic and steric factors, as well as by the nature of the nucleophile and the reaction medium, including the presence of Lewis acids and bases. ${ }^{66}$ The reactivity of 2(chloromethyl)oxiranes with selenide ions has also been investigated. ${ }^{67}$ Furthermore, a catalytic tellurium-based procedure for the transposition of allylic hydroxyl groups and carbon-carbon double bonds has also been developed by Dittmer and coworkers. $^{68}$

Tellurium-mediated methodologies represent useful tools for the synthesis of complex or biologically active molecules. For example, a tellurium transposition reaction has been used as a key step for in the Dittmer and co-workers' synthesis of optically active boivinose. $^{69}$

\section{Ring-opening of four-, five-, and six-membered heterocycles with chalcogen nucleophiles}

Not only three membered heterocycles, but also larger rings (four-, five-, six-membered derivatives) were found to undergo ring opening with chalcogen-containing nucleophiles.

It was reported that cyclic ethers (THF) upon treatment with dialkylor alkylphenylselenium dibromides in the presence of sodium borohydride furnished $\omega$-hydroxyalkyl alkyl or phenyl selenides (Scheme 45). ${ }^{70}$

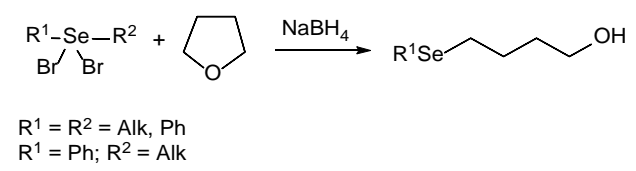

Scheme 45: Ring opening of THF with dialkyl- or alkylphenylselenium dibromides.

Reaction of cyclic ethers with tellurium halides have been rarely described. However, an unexpected ring opening of tetrahydrofuran was observed when $\mathrm{TeBr}_{4}$ was reacted with triphenylphosphine in THF, providing $\mathrm{Ph}_{3} \mathrm{PO}\left(\mathrm{CH}_{2}\right)_{4} \mathrm{TeBr}_{4} 70$ as reported in Scheme $46 .^{71}$

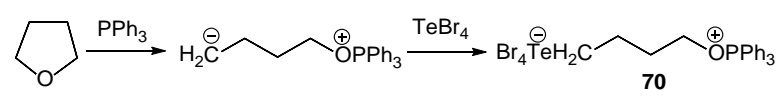

Scheme 46: Ring opening of THF with $\mathrm{PPh}_{3} / \mathrm{TeBr}_{4}$.

The structure of $\mathbf{7 0}$ was elucidated by $\mathbf{X}$-ray. It is formally a tellurium containing zwitterionic structure, which represents a very rare compound, with the negative charge on the Te atom and the positive charge on the $P$ atom. ${ }^{71}$

Ring-opening of tetrahydrofuran was also observed when the in situ formed PhSeZnSePh 71a was reacted in THF with acyl chlorides to 
prepare selenol esters. In fact, when the seleniun-zinc complex was generated by reduction of diphenyl diselenide in the presence of zinc( 0 ) and trifluoromethansulfonic acid ( $\mathrm{TfOH}$ ) in THF, followed by addition of the acyl chloride, besides the desired selenol ester $\mathbf{7 2}$, products arising from the ring opening of THF were unexpectedly observed (Scheme 47). ${ }^{72}$

Depending on the nature of the acyl chloride (EDG or EWG on the aromatic rings) both side products $\mathbf{7 3}$ and $\mathbf{7 4}$ were observed in comparable amount with respect the selenol ester $\mathbf{7 2}$, showing that the ring-opening of THF competes with the reaction of the selenolate with acyl chlorides. Despite several attempts were performed, the selectivity of the reaction was not improved. ${ }^{72}$

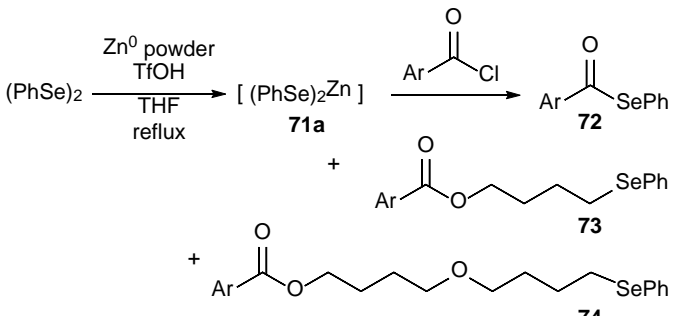

74

Scheme 47: Ring opening of THF with PhSeZnSePh 71.

Ring opening reaction of selenium nucleophiles was also carried out with 2-oxazolines 75 to prepare chiral $\beta$-seleno amides. ${ }^{73}$ The reaction proceeded through the regio- and chemoselective attack of aryl or alkyl selenide anions at $C(5)$ of the ring, affording chiral $\beta$ seleno amides 7 , bearing different functional groups. It was demonstrated that the nature of the substituent $R^{1}$ on the oxazolidine does not play a significant role, and that the aromatic diselenides with EWG group (Cl) or EDG (MeO) do not evidence a significant electronic influence (Scheme 48). ${ }^{73}$

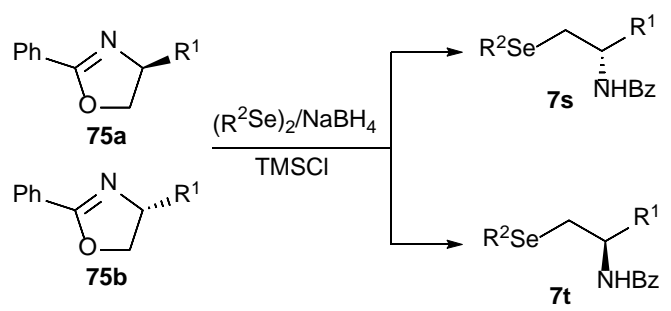

$\mathrm{R}^{1}={ }^{i} \mathrm{Pr}, \mathrm{Bn},\left(\mathrm{CH}_{2}\right)_{2} \mathrm{SMe}, \mathrm{CH}_{2} \mathrm{OH}, \mathrm{CH}_{2} \mathrm{OBn}, \mathrm{CH}_{2} \mathrm{OEt}, \mathrm{CO}_{2} \mathrm{Me}$ $\mathrm{R}^{2}=\mathrm{Ph}, 2,4,6-\mathrm{Me}_{3} \mathrm{Ph}, p$-CIPh, $p$-MeOPh, Bn, Bu

Scheme 48: Ring opening of 2-oxazolines 75 with selenium nucleophiles.

It is noteworthy that through this procedure a selenocysteine derivative was synthesized when 2-oxazoline-4-carboxylate was reacted with phenylselenolate.

Taking into account that mixed Se, $\mathrm{N}$ compounds represent an efficient class of ligands is asymmetric synthesis, the Pd-catalyzed asymmetric allylic alkylation of propenyl acetate with dimethyl malonate was studied in the presence of suitably substituted chiral $\beta$-seleno amides $\mathbf{7}$. Alkylated products $\mathbf{7 6}$ were obtained in good yield with high stereoselectivity ( $98 \%$ ee). The reaction was performed with a variety of dialkyl malonates and different $\beta$ seleno amides as chiral ligands, allowing to obtain the alkylated products in high yields and with different levels of enantioselectivity (Scheme 49). ${ }^{73}$

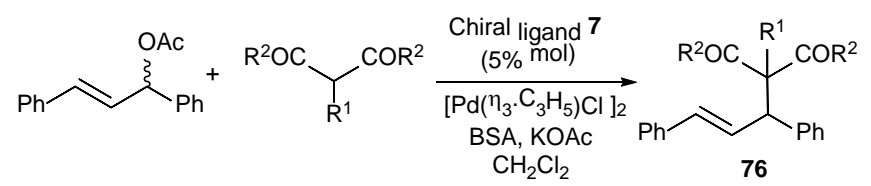

Scheme 49: $\beta$-Seleno amides as chiral ligands in asymmetric synthesis.

Ligands containing other functional groups such as thioether, alcohol, ester behaved as less efficient catalytic systems in terms of yields and enantioselectivity (essentially racemic products were obtained). ${ }^{73}$

Ring-opening of oxazolines by selenium nucleophiles was also performed with diselenides under indium-mediated conditions. Both indium iodide and indium metal/RHal were used to form indium selenolates via oxidative insertion (Scheme 50). ${ }^{74}$

As proposed for the ring-opening of aziridines, an $\ln ($ III) complex is generated, which promotes a regio- and chemoselective ringopening of oxazolines to obtain non-racemic $\beta$-seleno amides and selenocysteine derivatives under mild conditions. Diphenylditelluride was also reacted, to afford $\beta$-telluro amides. ${ }^{74}$

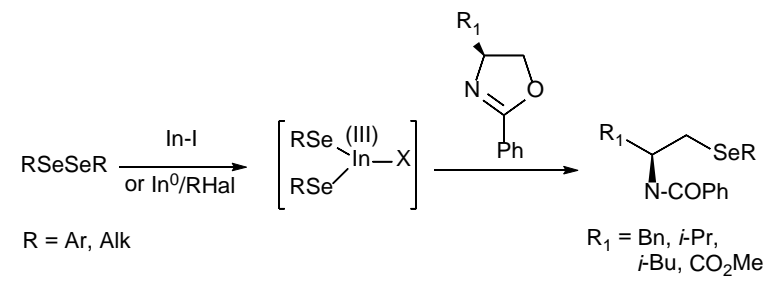

Scheme 50: Indium iodide-mediated ring opening of oxazolines.

Reaction of 2-oxazolines-4-carboxylate with Woolins' reagent (WR) and $\mathrm{NaBH}_{4}$ was also investigated by Iwaoka and co-workers, and represents an alternative procedure to access optically pure Lselenocysteine and $\alpha$-methyl-L-selenocysteine derivatives (Scheme 51). ${ }^{75}$

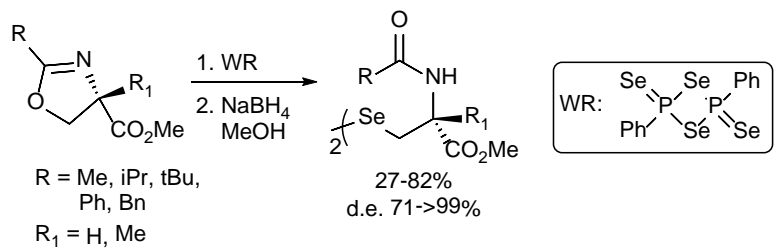

Scheme 51: Oxazolines ring opening with Woolins' reagent.

Chiral $\beta$-seleno amines 7 were also obtained via a regio- and chemoselective ring-opening of various $N$-protected-2oxazolidinones $\mathbf{7 7}$ by phenyl selenolate, followed by 
decarboxylation. In a similar manner phenyl tellurolate gave $\beta$ telluro amines 8 (Scheme 52 ). ${ }^{76}$

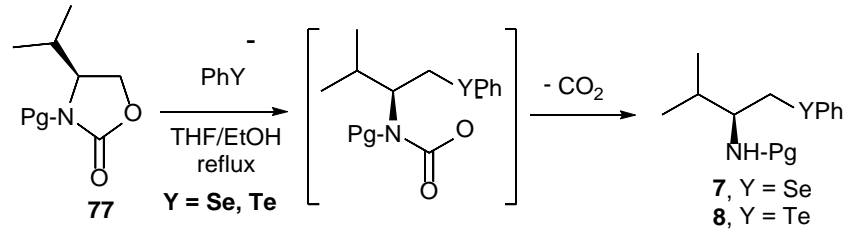

Scheme 52: Ring-opening of $N$-protected-2-oxazolidinones by phenyl selenolate and tellurolate.

The reaction was also performed with $\mathrm{Li}_{2} \mathrm{Se}_{2}$ as nucleophile, affording the $\beta$-amino diselenide 41c (Scheme 53), which was demonstrated to act as catalyst in the reaction of $\mathrm{Et}_{2} \mathrm{Zn}$ with aldehydes. $^{76}$
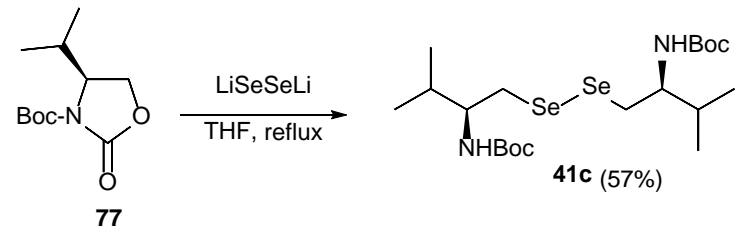

Scheme 53: Ring-opening of $\mathbf{N}$-protected-2-oxazolidinones $\mathbf{7 7}$ with $\mathrm{Li}_{2} \mathrm{Se}_{2}$.

Selenium anions ( $\mathrm{Na}_{2} \mathrm{Se}_{2}$ and $\mathrm{Na}_{2} \mathrm{Se}$ ), prepared from selenium and sodium borohydride, were employed as nucleophiles in ringopening of lactones 78. ${ }^{77}$ Krief and co-workes reported the reaction with $\gamma$-butyrolactone $\mathbf{7 8 a}$ to obtain diselenide $\mathbf{7 9 a}$ or selenide $\mathbf{8 0 a}$ as major compounds depending on the ratio $\mathrm{Se}(0) / \mathrm{NaBH}_{4}$ and on the ring opening reaction conditions (Scheme 54). ${ }^{74}$

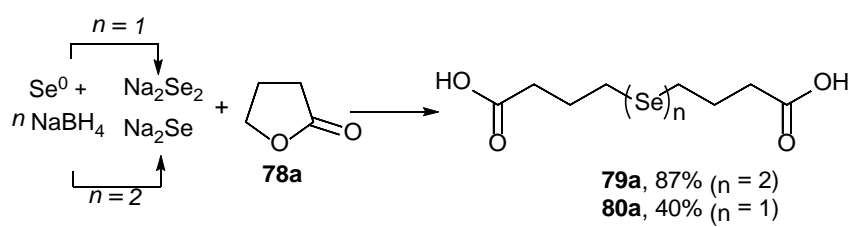

Scheme 54: Ring-opening of $\gamma$-butyrolactone with $\mathrm{Na}_{2} \mathrm{Se}$ and $\mathrm{Na}_{2} \mathrm{Se}_{2}$.

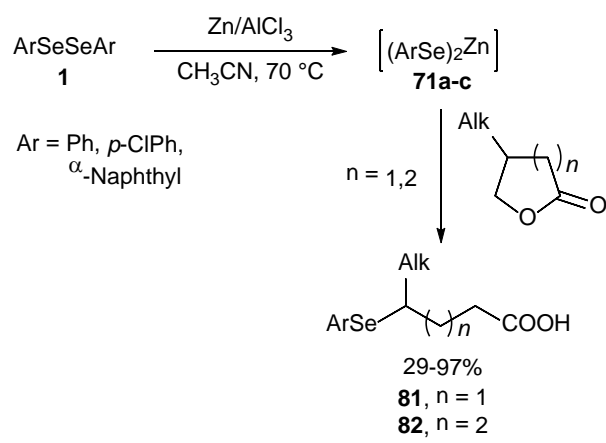

Scheme 55: Nucleophilic cleavage of lactones with zinc selenolates. $\gamma$ - and $\delta$ - Lactones were efficiently subjected to nucleophilic cleavage with zinc selenolates, prepared from aryl diselenides and $\mathrm{Zn} / \mathrm{AlCl}_{3}$, affording the corresponding carboxylic acids $\mathbf{8 1}$ and $\mathbf{8 2}$ (Scheme 55). ${ }^{78}$

When acidic protons were contained in the substrate $(\mathbf{7 8 b})$, the loss of carbon dioxide was observed, leading to the isolation of the corresponding seleno ketones 83 (Scheme 56). ${ }^{78}$

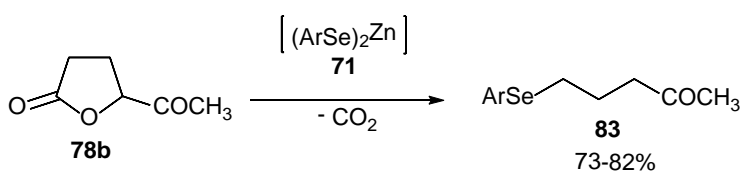

Scheme 56: Nucleophilic ring opening of lactones with zinc selenolates and decarboxylation.

An interesting example involving ring-opening of lactones is the treatment of the serine $\beta$-lactone $\mathbf{8 4}$ with dilithium chalcogenides, obtained by reduction of elemental selenium or tellurium with super hydride ( $\left.\mathrm{LiEt}_{3} \mathrm{BH}\right)$. Optically active L-selenocystine 85 and Ltellurocystine 86 (with $\mathrm{Li}_{2} \mathrm{Y}_{2}$ ) or L-selenolanthionine 87 and $\mathrm{L}$ tellurolanthionine 88 (with $\left(\mathrm{Li}_{2} \mathrm{Y}\right)$ were readily prepared in good yields (Scheme 57). ${ }^{79}$

Reaction of serine $\beta$-lactone with phenyl telluride anions allowed to synthesize tellurocysteine conjugates $8 \mathbf{8 t}^{79}$

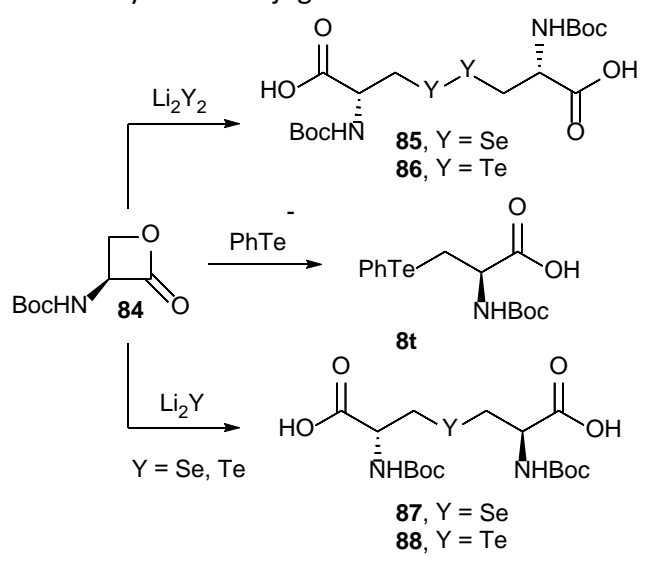

Scheme 57: Ring opening of serine $\beta$-lactone with selenium and tellurium nucleophiles.

Other five membered heterocycles such as 5-membered cyclic sulfamidates $\mathbf{8 9}$ were found to behave as versatile electrophiles towards phenyl selenolate, generated by reaction of diphenyl diselenide with rongalite $/ \mathrm{K}_{2} \mathrm{CO}_{3}$, to give enantiopure $\beta$-amino phenyl selenides 7 in high yields (Scheme 58 ). ${ }^{80} \mathrm{~A}$ regioselective attack of the nucleophile at $C(4)$ was observed, irrespective to the type of substituents. In addition, differently from what observed with activated and non-activated aziridines, the reactivity of sulfamidates was not depending on the nature of the group on the nitrogen.

Sterically hindered substrates reacted slowly to afford the desired products in comparable yields (79-81\%). Ring cleavage of 6- 
membered cyclic sulfamidates was achieved as well through this approach, affording $\gamma$-amino selenides in good yield.

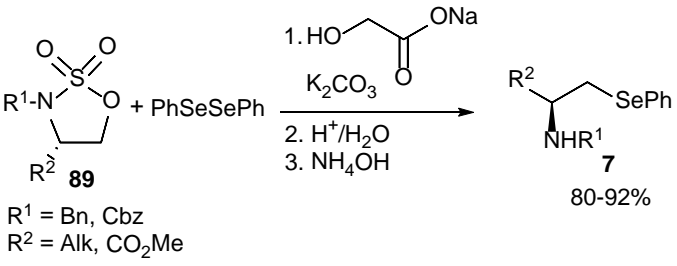

Scheme 58: Synthesis of $\beta$-amino selenides from cyclic sulfamidates.

Also cyclic sulfamidates underwent nucleophilic cleavage upon treatment with potassium selenocyanate followed by reductive dimerization induced by ammonium thiomolybdate $\left[\left(\mathrm{BnNEt}_{3}\right)_{2} \mathrm{MoS}_{4}\right]$ through one-pot multistep procedure. Differently substituted 5-membered cyclosulfamidates 89 were reacted, to provide a wide variety of $\mathrm{N}$-alkyl- $\beta$-amino diselenides 41 in high yields, including selenocystine derivatives $\left(R^{2}=\mathrm{CO}_{2} \mathrm{Me}\right)$ (Scheme 59). ${ }^{81}$
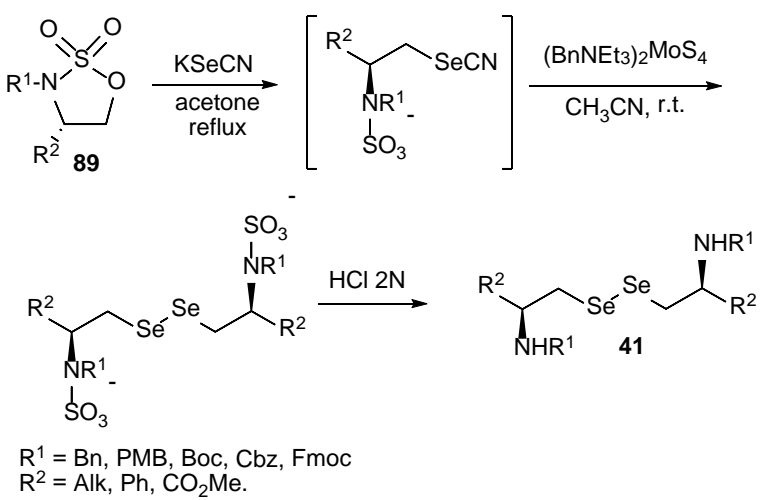

Scheme 59: Nucleophilic ring opening of cyclic sulfamidates with $\mathrm{KSeCN}$ - ammonium thiomolybdate.

Exclusive attack of $\mathrm{KSeCN}$ at the $\mathrm{C}-\mathrm{O}$ bond of sulfamidate was observed, followed by attack of $\mathrm{MoS}_{4}{ }^{-}$on the Se-atom. Hydrolysis of the intermediate complex gave amino diselenides $\mathbf{4 1}$.

\section{Reactions of activated cyclopropanes with selenium nucleophiles}

Chalcogenated nucleophiles were also employed in the reaction with carbocycles such as activated cyclopropane derivatives.

Methylenecyclopropanes 90 (MCPs) found applications as useful building blocks in synthetic organic chemistry. Heating MCPs in the presence of diphenyl diselenide 1 without solvent allowed to obtain the corresponding ring-opened unsaturated products 91 (Scheme 60). ${ }^{82}$ MCPs were reacted also in the presence of Lewis $\mathrm{acid} / \mathrm{Se}$ (or S) to access homoallylic selenols (or thiols) derivatives. $^{82 \mathrm{~b}}$

Based on the finding that $\mathrm{PhSeSePh}$ gave phenylselenyl radical by thermal cleavage, a radical mechanism was proposed for this reaction. A primary addition of the radical to the double bond caused a fast ring-opening via a homoallylic rearrangement. The reaction of the formed alkyl radical with a second equivalent of diselenide through a homolitic substitution $\left(\mathrm{S}_{H}\right)$ afforded alkyl-vinyl1,3-bis(phenyl selenides) 91, with the regeneration of the selenyl radical (Scheme 60)

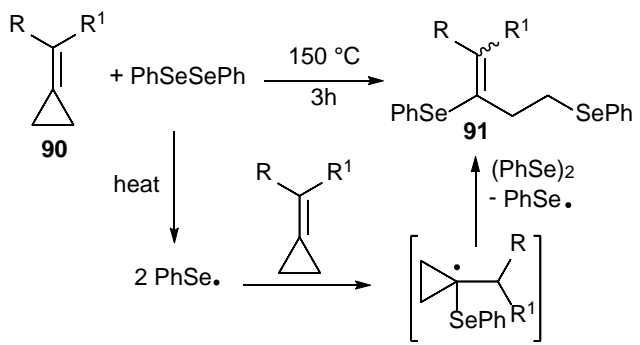

$$
\begin{aligned}
& \mathrm{R}=\mathrm{R}^{1}=\mathrm{Ph}, p-\mathrm{Tol}, p-\mathrm{MeOPh}, p-\mathrm{ClPh}, p-\mathrm{FPh} \\
& \mathrm{R}=\mathrm{Ph} ; \mathrm{R}^{1}=p \text {-MeOPh } \\
& \mathrm{R}=\mathrm{Ph}, \mathrm{R}^{1}=p-\mathrm{CIPh}
\end{aligned}
$$

Scheme 60: Synthesis of alkyl-vinyl-1,3-bis(phenyl selenides).

Reaction with unsymmetric methylenecyclopropanes afforded an almost equimolar mixture of $E$ - and Z-isomers. ${ }^{82}$

Under similar conditions, reaction of arylvinylidenecyclopropanes 92 with diphenyl diselenide at $150{ }^{\circ} \mathrm{C}$ led to 1,2diarylselenocyclopentene derivatives 93 (Scheme 61). ${ }^{83}$
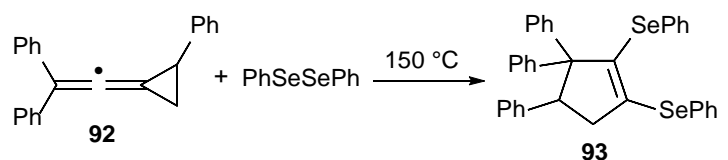

Scheme 61: Synthesis of 1,2-diarylselenocyclopentene derivatives.

As already reported for lactones, zinc selenolates $\mathbf{7 1}$, obtained for reductive cleavage of diaryl diselenides with $\mathrm{Zn} / \mathrm{AlCl}_{3}$, was efficient also in the nucleophilic the ring-opening of monoactivated cyclopropanes bearing ketone, aldehyde, acid or nitrile moieties, to give the corresponding $\gamma$-arylselenyl ketone, acid, nitrile, and aldehyde in good to high yields under mild conditions (Scheme 62). In the case of the ester derivative, no product was observed due to the competitive cleavage of the acyl-oxygen bond with the formation of phenol in rather quantitative yield. ${ }^{84}$

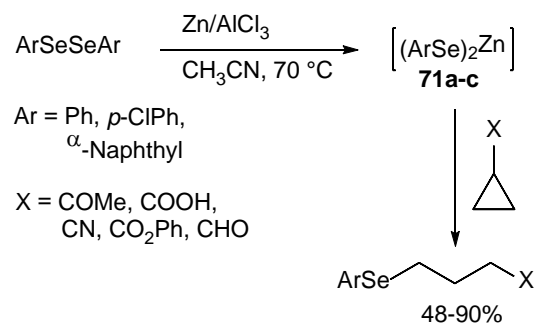

Scheme 62: Synthesis of $\gamma$-substituted aryl alkyl selenides. 
A variety of organoselenium compouds was prepared by nucleophilic ring opening of doubly activated cyclopropanes by diselenides $/ \mathrm{NaBH}_{4}$ (Scheme 63). ${ }^{85}$

$$
\underset{\substack{\mathrm{X}=\mathrm{H}, \mathrm{Me}, \mathrm{Br}, \mathrm{Cl}, \mathrm{NO}_{2}, \mathrm{CO} \mathrm{X}_{2} \mathrm{Me}, \mathrm{CN}, \mathrm{MeO}}}{0{ }^{\circ} \mathrm{C} \text { to r.t. }}
$$

Scheme 63: Ring opening of doubly activated cyclopropanes by selenolates.

Besides the most commonly used diphenyl diselenide, differently substituted aryl diselenides were reduced by sodium hydride. The arylselenolates were reacted with varius EWG-activated cycopropanes, to yield a wide range of $\gamma$-bi-functionalized selenides $94 .^{85}$

\section{Conclusions}

Organoselenides and organotellurides are valuable compounds both in biology and in organic synthesis. The capability of organochalcogenides to undergo chemo-, regio-, and stereoselective transformations attracted considerable interest during the last decades. A growing number of organoselenides and organotellurides find wide application in medicinal chemistry, biology, and materials science. Consequently, new methods to synthesise functionalised selenium- and telluriumcontaining small molecules have been developed. In this context, nucleophilic ring opening reactions (NRORs) of heterocycles represent a convenient and versatile tool to access a plethora of variously functionalised systems. The availability of a wide variety of chalcogen-containing nucleophiles, also employable under mild conditions, increases the synthetic utility of such ring-opening-based procedures, enabling a facile and convenient synthesis of densely functionalised systems.

\section{Conflicts of interest}

There are no conflicts to declare.

\section{Acknowledgements}

We thank MIUR-Italy ("Progetto Dipartimenti di Eccellenza 2018-2022" allocated to Department of Chemistry "Ugo Schiff"').

\section{Notes and references}

1 (a) E. J. Lenardão, C. Santi and L. Sancineto, New Frontiers in Organoselenium Compounds, Springer, New York, 2018; (b)
Organoselenium Chemistry: Synthesis and Reactions, ed. T. Wirth, Wiley-VCH, Weinheim, Germany, 2012; (c) M. Gao, R. Wang, F. Yu, B. Li and L. Chen, J. Mater. Chem. B, 2018, 6, 6637; (d) P. F. Li, T. B. Schon and D. S. Seferos, Angew. Chem. Int. Ed., 2015, 54, 9361; (e) C. W. Nogueira, G. Zeni and J. B. T. Rocha, Chem. Rev., 2004, 104, 6255 and references cited therein; (f) V. Domazetovic, F. Fontani, D. Tanini, V. D'Esopo, C. Viglianisi, G. Marcucci, L. Panzella, A. Napolitano, M. L. Brandi, A. Capperucci, S. Menichetti, M. T. Vincenzini and T. Iantomasi, Chem. Biol. Interact., 2017, 275, 13; (g) F. V. Singh and T. Wirth, in Organoselenium Compounds in Biology and Medicine: Synthesis, Biological and Therapeutic Treatments, ed. V. K. Jain and K. I. Priyadarsini, Royal Society of Chemistry, London, 2018, chapter 3 and references cited therein; (h) L. D. Carrol and M. J. Davies, in Organoselenium Compounds in Biology and Medicine: Synthesis, Biological and Therapeutic Treatments, ed. V. K. Jain and K. I. Priyadarsini, Royal Society of Chemistry, London, 2018, chapter 9 and references cited therein; (i) A. R. Patra, S. S. Roy, A. Basu, A. Bhuniya, A. Bhattachariee, S. Hajra, U. H. Sk, R. Baral and S. Bhattacharya, Sci. Rep., 2018, 8, 2194; (j) H. J. Reich and R. J. Hondal, ACS Chem. Biol., 2016, 11, 821.

2 K. B. Sharpless and R. F. Lauer, J. Am. Chem. Soc., 1973, 95, 2697.

3 (a) M. Iwaoka, in Organoselenium Chemistry: Synthesis and Reactions, ed. T. Wirth, Wiley-VCH, Weinheim, Germany, 2012, chapter 2 and references cited therein; (b) S. Tomoda and M. Iwaoka, J. Chem. Soc. Chem. Commun., 1988, 1283; (c) Y. Nishibayashi, J. D. Singh, S. Fukuzawa and S. Uemura, J. Chem. Soc. Perkin Trans. 1, 1995, 2871.

4 H. S. Shin, Y. G. Jung, H. K. Cho, Y. G. Park and C. G. Cho, Org. Lett., 2014, 16, 5718.

5 B. M. Trost, W. Tang and F. D. Toste, J. Am. Chem. Soc., 2005, 127, 14785 .

6 G. Pandey, R. fernades and D. Dey, Synlett, 2018, 29, 805.

7 Y. Gao, Y. Wei and D. Ma, Org. Lett., 2019, 21, 1384.

8 (a) D. Tanini, A. Capperucci, C. T. Supuran and A. Angeli, Bioorg. Chem., 2019, 87, 516; (b) A. Angeli, D. Tanini, A. Nocentini, A. Capperucci, M. Ferraroni, P. Gratteri and C. T. Supuran, Chem. Commun., 2019, 55, 648.

9 (a) A. S. Hodage, P. P. Phadnis, A. Wadawale, K. I. Priyadarsini and V. K. Jain, Org. Biomol. Chem., 2011, 9, 2992; (b) A. L. Braga, E. E. Alberto, L. C. Soares, J. B. T. Rocha, J. H. Sudati and D. H. Roos, Org. Biomol. Chem., 2009, 7, 43; (c) Y. You, K. Ahsan and M. R. Detty, J. Am. Chem. Soc., 2003, 125, 4918.

10 J.-X. Wang, Y. Xi, Y. Hu, Z. Du and K. Zhao, Synth. Commun., 2000, 15, 2661.

11 P. C. Silva, E. L. Borges, D. B. Lima, R. G. Jacob, E. J. Lenardão, G. Perin and M. S. Silva, Arkivoc, 2016, (v), 376.

12 V. Ganesh and S. Chandrasekaran, Synthesis, 2009, 19, 3267.

13 D. Sui, F. Wu, Q. Xu and X. Yu, J. Chem. Res., 2011, 288.

14 B. Movassagh and M. Shamsipoor, Synlett, 2005, 8, 1316.

15 C. Santi, S. Santoro, L. Testaferri and M. Tiecco, Synlett, 2008, 10, 1471.

16 A. L. Braga, R. S. Schwab, E. E. Alberto, S. M. Salman, J. Vargas and J. B. Azaredo, Tetrahedron Lett., 2009, 50, 2309.

17 C. Santi, S. Santoro, B. Battistelli, L. Testaferri and M. Tiecco, Eur. J. Org. Chem., 2008, 5387.

18 S. M. Salman, R. S. Schwab, E. E. Alberto, J. Vargas, L. Dornelles, O. E. Rodrigues and A. L. Braga, Synlett, 2011, 1, 69.

19 S. M. Salman, S. Narayanaperumal, R. S. Schwab, C. R. Bender, O. E. D. Rodrigues and L. Dornelles, RSC Adv., 2012, 2, 8478 .

20 J. Dowsland, F. McKerlie and D. J. Procter, Tetrahedron Lett., 2000, 41, 4923.

21 A. L. Braga, P. H. Schneider, M. W. Paixão, A. M. Deobald, C. Peppe and D. P. Bottega J. Org. Chem., 2006, 71, 4305. 
22 F. Vargas and J. V. Comasseto, J. Organomet. Chem., 2009, 694, 122.

23 N. Devan, P. R. Sridhar, K. Prabhu and S. Chandrasekaran, J. Org. Chem., 2002, 67, 9417.

24 (a) A. Capperucci, A. Degl'Innocenti and C. Tiberi, Synlett, 2011, 15, 2248; (b) A. Degl'Innocenti, S. Pollicino and A Capperucci, Chem. Commun. 2006, 4881; (c) A. Degl'Innocenti, A. Capperucci, A. Cerreti, S. Pollicino, S. Scapecchi, I. Malesci and G. Castagnoli, Synlett, 2005, 20, 3063; (d) A. Capperucci and D. Tanini, Phosphorus, Sulfur Silicon Relat. Elem., 2015, 190, 1320.

25 M. R. Detty, Tetrahedron Lett., 1978, 19, 5087.

26 A. Capperucci, C. Tiberi, S. Pollicino and A. Degl'Innocenti, Tetrahedron Lett., 2009, 50, 2808.

27 K. Sasaki, Y. Aso, T. Otsubo, F. Ogura, Tetrahedron Lett., 1985, 26, 453.

28 D. Tanini, C. Borgogni and A. Capperucci, New J. Chem., 2019, 43, 6388

29 D. Tanini, A. Grechi, S. Dei, E. Teodori and A. Capperucci, Tetrahedron, 2017, 73, 5646.

30 A. Angeli, D. Tanini, A. Capperucci, G. Malevolti, F. Turco,M. Ferraroni and C. T. Supuran, Bioorg. Chem., 2018, 81, 642.

31 (a) M. Besev and L. Engman, Org. Lett., 2002, 4, 3023; (b) A. Alcaide and A. Llebaria, Tetrahedron Lett., 2012, 53, 2137.

32 Y. Nishiyama, H. Ohashi, K. Itoh and N. Sonoda, Chem. Lett., 1998, 159.

33 A. Cravador and A. Krief, Tetrahedron Lett., 1981, 22, 2491.

34 M. Tiecco, L. Testaferri, F. Marini, S. Sternativo, F. Del Verme, C. Santi, L. Bagnoli and A. Temperini, Tetrahedron, 2008, 64, 3337.

35 M. Senatore, A. Lattanzi, S. Santoro, C. Santi and G. Della Sala, Org. Biomol. Chem., 2011, 9, 6205.

36 R. Sridhar, B. Srinivas, K. Surendra, N. S. Krishnaveni and K. R. Rao, Tetrahedron Lett., 2005, 46, 8837.

37 M. H. Yang, G. B. Yan and Y. F. Zheng, Tetrahedron Lett., $2008,49,6471$.

38 M. Yang, C. Zhu, F. Yuan, Y. Huang and Y. Pan, Org. Lett., 2005, 7, 1927.

39 T. Leng, G. Wu, Y.-B. Zhou, W. Gao, J. Ding, X. Huang, M. Liu and H. Wu, Adv. Synth. Catal., 2018, 360, 4336.

40 L. Min, G. Wu, M. Liu, W. Gao, J. Ding, J. Chen, X. Huang and H. Wu, J. Org. Chem., 2016, 81, 7584.

41 G. Wu, L. Min, H. Li, W. Gao, J. Ding, X. Huang, M. Liu and H. Wu, Green Chem., 2018, 20, 1560.

42 S. Berlin, C. Ericsson and L. Engman J. Org. Chem., 2003, 68, 8386.

43 J. Alvano Pérez-Bautista, M. Sosa-Rivadeneyra, L. Quintero, H. Höpfl, F. A. Tejeda-Dominguez and F. Sartillo-Piscil Tetrahedron Lett., 2009, 50, 5572.

44 L. Liu, Y. Sun, J. Wang, W. Ou, X. Wang, and S. Huang Synlett, 2019, 30, 748.

45 S. Diaz, J. Cuesta, Gonzàlez and J. Bonjoch J. Org. Chem., 2003, 68, 7400.

46 M. Gruttadauria, C. Aprile, F. D’Anna, P. Lo Meo, S. Riela and R. Noto, Tetrahedron, 2001, 57, 6815.

47 M. Gruttadauria, C. Aprile and R. Noto, Tetrahedron Lett. 2002, 43, 1669.

48 O. E. D. Rodrigues, D, de Souza, L. C. Soares, L. Dornelles, R. A. Burrow, H. R. Appelt, C. F. Alves, D. Alves, and A. L. Braga Tetrahedron Lett., 2010, 51, 2237.

49 R. F. Affeldt, F. P. Santos, R. S. da Silva,b O. E. D. Rodrigues, L. A. Wessjohann and D. S. Lüdtke RSC Adv., 2016, 6, 93905.

50 A. L. Braga, D. S. Lüdtke, M. W. Paixão, E. E. Alberto, H. A. Stefani and L. Juliano Eur. J. Org. Chem., 2005, 5, 4260.

51 V. Satheesh, S. V. Kumar M. Vijay, D. Barik and T. Punniyamurthy Asian J. Org. Chem., 2018, 7, 1583.

52 A. L. Braga, M. W. Paixão, D. S. Lüdtke, C. C. Silveira and O. E. D. Rodrigues Org. Lett., 2003, 5, 2635.
53 D. Tanini, A. Degl'Innocenti and A. Capperucci, Eur. J. Org. Chem., 2015, 357

54 A. Capperucci, D. Tanini, C. Borgogni and A. Degl'Innocenti, Heteroat. Chem., 2014, 25, 678.

55 D. Tanini, C. Tiberi, C. Gellini, P. R. Salvi and A. Capperucci, Adv. Synth. Catal., 2018, 360, 3367.

56 (a) D. Tanini, S. Scarpelli, E. Ermini and A. Capperucci, Adv. Synth. Catal., 2019, DOI: 10.1002/adsc.201900168; (b) D. Tanini, B. Lupori, G. Malevolti, M. Ambrosi, P. Lo Nostro and A. Capperucci, Chem. Commun., 2019, DOI: 10.1039/C9CC02427A.

57 D. Tanini, C. Bonardi, C. Viglianisi, A. Capperucci and S. Menichetti, Catalysts, 2019, 9, 333.

58 (a) C. Viglianisi, C. Bonardi, E. Ermini, A. Capperucci, S. Menichetti and D. Tanini, Synthesis, 2019, 51, 1819; (b) S. Menichetti, K. Vasa, D. Tanini, A. Capperucci, R. Amorati, L. Valgimigli, A. Baschieri and C. Viglianisi, Chem. Eur. J., 2019, DOI: $10.1002 /$ chem.201901537

59 (a) A. Angeli, D. Tanini, A. Capperucci and C. T. Supuran, Bioorg. Chem., 2018, 76, 268; (b) A. Angeli, D. Tanini, A. Capperucci and C. T. Supuran, ACS Med. Chem. Lett., 2017, 8, 1213; (c) A. Angeli, D. Tanini, C. Viglianisi, L. Panzella, A. Capperucci, S. Menichetti and C. T. Supuran, Bioorg. Med. Chem., 2017, 25, 2518.

60 (a) D. Tanini, A. Grechi, L. Ricci, S. Dei, E. Teodori, A. Capperucci, New J. Chem., 2018, 42, 6077; (b) D. Tanini, V. D'Esopo, D. Chen, G. Barchielli and A. Capperucci, Phosphorus, Sulfur Silicon Relat. Elem., 2017, 192, 166.

61 D. Sureshkumar, T. Gunasundari, V. Saravanan and S. Chandrasekaran, Tetrahedron Lett., 2007, 48, 623. For a review see: D. Sureshkumar, P. Gopinath and S. Chandrasekaran, Chimia, 2012, 66, 921.

62 D. Sureshkumar, V. Ganesh and S. Chandrasekaran, J. Org. Chem., 2007, 72, 5313.

63 D. Sureshkumar, S. Koutha and S. Chandrasekaran, Eur. J. Org. Chem., 2007, 4543

64 B. Chao and D. C. Dittmer, Tetrahedron Lett., 2001, 42, 5789.

65 A. S. Pepito and D. C. Dittmer, J. Org. Chem., 1997, 62, 7920

66 D. C. Dittmer, Y. Zhang and R. P. Discordia, J. Org. Chem., 1994, 59, 1004

67 G. Polsen and D. C. Dittmer, J. Org. Chem., 1988, 53, 791

68 A. Kumar and D. C. Dittmer, Tetrahedron Lett., 1994, 35, 5583.

69 A. S. Pepito and D. C. Dittmer, J. Org. Chem., 1994, 59, 4311.

70 T. Takanohashi, H. Funakoshi and S. Akabori, Synth. Commun., 1994, 24, 2733.

71 S. M. Kunnari, R. OilunKaniemi, R. S. Laitinen and M. Ahlgrén, J. Chem. Soc., Dalton Trans., 2001, 3417

72 G. Bellino, M. Scisciani, J. Pinto Vargas, L. Sancineto, L. Bagnoli, F. Marini, D. S. Lüdtke, E. J. Lenardao and C. Santi, J. Chem., 2016, 2849140.

73 (a) A. L. Braga, F. Vargas, J. A. Sehnem and R. C. Braga, J. Org. Chem. 2005, 70, 9021; (b) F. Vargas, J. A. Sehnem, F. Z. Galetto and A. L. Braga, Tetrahedron, 2008, 64, 392.

74 (a) A. L. Braga, F. Vargas, F. Z. Galetto, M. W. Paixão, R. S. Schwab, and P. S. Taube, Eur. J. Org. Chem. 2007, 5327; (b) A. L. Braga, F. Z. Galetto, P. S. Taube, M. W. Paixão, C. C. Silveira, D. Singh and F. Vargas, J. Organomet. Chem., 2008, 693, 3563.

75 M. Iwaoka, S. Ito, I. Miyazaki and M. Michibata Proc. Natl. Acad. Sci., India, Sect. A Phys. Sci., 2016, 86, 499.

76 J. A. Sehnem, F. Vargas, P. Milani, V. Nascimento and A. L. Braga, Synthesis, 2008, 1262.

77 A. Krief and M. Derock, Synlett, 2005, 6, 1012.

78 M. Nazari and B. Movassagh, Tetrahedron Lett., 2009, 50, 438. 
79 A. Schneider, O. E. D. Rodrigues, M. W. Paixão, H. R. Appelt, A. L. Braga and L. A. Wessjohann, Tetrahedron Lett., 2006, 47, 1019.

80 C. Venkateswarlu, B. Datta and S. Chandrasekaran, RSC Adv., 2014, 4, 42952.

81 N. B. R. Baig, R. N. Chandrakala, V. S. Sudhir and S. Chandrasekaran, J. Org. Chem. 2010, 75, 2910.

82 (a) L.-P. Liu and M. Shi, Chem. Commun., 2004, 2878; (b) M. Shi, M. Jiang and L.-P. Liu, Org. Biomol. Chem., 2007, 5, 438.

83 M. Shi, J.-M. Lu and G.-C. Xu Tetrahedron Lett., 2004, 46 , 4745.

84 M. Nazari and B. Movassagh, Synlett, 2009, 11, 1803.

85 P. Gopinath, R. N. Chandrakala and S. Chandrasekaran, Synthesis, 2015, 47, 1488. 